Article

\title{
Systematic Multiscale Models to Predict the Compressive Strength of Cement Paste as a Function of Microsilica and Nanosilica Contents, Water/Cement Ratio, and Curing Ages
}

\author{
Chiya Y. Rahimzadeh ${ }^{1,2, *}$, Ahmed Salih ${ }^{3}$ (D) and Azeez A. Barzinjy ${ }^{4,5}$ \\ 1 Civil Engineering Department, Faculty of Engineering, Soran University, Soran 44008, Iraq \\ 2 Scientific Research Centre, Soran University, Soran 44008, Iraq \\ 3 Civil Engineering Department, College of Engineering, University of Sulaimani, Sulaymaniyah 46001, Iraq; \\ ahmed.mohammed@univsul.edu.iq \\ 4 Department of Physics, College of Education, Salahaddin University-Erbil, Erbil 44001, Iraq; \\ azeez.azeez@su.edu.krd \\ 5 Department of Physics Education, Faculty of Education, Tishk International University, Erbil 44001, Iraq \\ * Correspondence: chiya.yousef@soran.edu.iq
}

\section{check for}

updates

Citation: Rahimzadeh, C.Y.; Salih, A.; Barzinjy, A.A. Systematic Multiscale Models to Predict the Compressive Strength of Cement Paste as a Function of Microsilica and Nanosilica Contents, Water/Cement Ratio, and Curing Ages. Sustainability 2022, 14, 1723. https://doi.org/ $10.3390 /$ su14031723

Academic Editors: Baojie He and Amir Mosavi

Received: 1 October 2021

Accepted: 10 January 2022

Published: 2 February 2022

Publisher's Note: MDPI stays neutral with regard to jurisdictional claims in published maps and institutional affiliations.

Copyright: (c) 2022 by the authors. Licensee MDPI, Basel, Switzerland. This article is an open access article distributed under the terms and conditions of the Creative Commons Attribution (CC BY) license (https:// creativecommons.org/licenses/by/ $4.0 /)$.

\begin{abstract}
Sustainable construction requires high-strength cement materials that additives with silica content could provide the requirements as well. In this study, the effect of the micro and nanosize of silica on the compressive strength of cement paste using different mathematical approaches is investigated. This study compares the strength of preferentially replaced cement pastes with microsilica (MS) and nanosilica (NS) incorporation by proposing several mathematical models. In this study, 205 data were extracted from the literature and analyzed. The modeling processes considered the most significant variables as input variables that influence the compression strength, such as curing time, which ranged between 3 and 90 days, the water-cement ratio, which varied between 0.4 and 0.85 , and NS ranged between 0 and $15 \%$. MS ranged between 0 and $40 \%$ based on the weight of cement. In this process, the compressive strength of cement paste modified with NS and MS was modeled using four different models, including the Linear Regression Model (LR), Nonlinear Model (NLR), Multi-Logistic Regression Model (MLR), and artificial neural network (ANN). The efficiency of the suggested models was evaluated using different statistical assessments, such as the Root Mean Squared Error (RMES), the Mean Absolute Error (MAE), Scatter Index (SI), Objective value (OBJ), and coefficient of determination $\left(\mathrm{R}^{2}\right)$. The findings revealed that the ANN model conducted better performance for predicting compressive strength for cement paste than the other models based on the statistical assessment. In addition, based on the statistical assessment of the sensitivity of parameters, NS had more of an effect on the compressive strength of cement paste, with $6.3 \%$ more than MS.
\end{abstract}

Keywords: microsilica (MS); nanosilica (NS); compressive strength; modeling; sensitivity

\section{Introduction}

Cement-based products are composition materials prepared from ordinary Portland cement (OPC), which is of prime significance in all building fields due to its vast usage and functions. A growing world population and relative requirements for infrastructure on one side, and enormous technical and product developments on the other have raised cement demand. In addition to being highly energy inefficient, the processing of cement and fine aggregates also poses a danger to the environment due to the release of unhealthy contaminants, including microparticles and $\mathrm{CO}_{2}$ gases [1]. It is estimated that cement clinkers' manufacturing is part of the substantial basis of the global $\mathrm{CO}_{2}$ gas footprint. The building industry is listed as one of the major causes of $\mathrm{CO}_{2}$ gas emissions. As demand for cement continues to increase, emissions are projected to become more substantial [2]. In addition, the building material strength, reliability, and maintenance costs are other critical 
topics of primary concern. Environmental sustainability includes advanced innovations to monitor and minimize $\mathrm{CO}_{2}$ emissions and energy usage and replace cement with supplementary cementitious materials, namely Pozzolans [1]. Diatomaceous earth [2], silica fume [3], volcanic ash [4], bottom ash, and husk/fly ash [5-7] are used in traditional pozzolans. Furthermore, several nanoparticles (NPs), for instance, carbon nanotubes [8], nano metakaolin [7,9-11], nanosilica (NS) [7,11-16], nano- $\mathrm{Al}_{2} \mathrm{O}_{3}[17,18]$, nano- $\mathrm{TiO}_{2}[19,20]$, nano- $\mathrm{CuO}[21]$, and nano- $\mathrm{Fe}_{2} \mathrm{O}_{3}[22,23]$, have also recently been investigated with rapid improvements in nanomaterial technology. In cement paste, these materials are mixed to substitute cement ideally to gain the necessary characteristics of the much more inexpensive materials, besides all the higher performance of the cement materials. Some NPs have high pozzolanic characteristics due to a finer particle volume and function as fillers, leading to uniform, dense, and compressed micro-structural materials [16].

Cement compositions' physical, chemical, and mechanical characteristics have been dramatically improved [24]. The ultra-thin NPs penetrate the voids found in the cement mix, leading to the void size being refined, the void volume decreasing, and the mechanism of the capillary in the voids being disconnected. As a result, the water permeability potential of the cement mix decreases, besides a coincident rise in the chemical resistance of the cement structures. The NPs build a micro-compact structure in cement paste that leads to a remarkably dense cement paste and increases the mechanical characteristics of the cement paste [25]. Silica fume (microsilica) has been used in concrete for the manufacture of high-performance cement-based materials. Micro/nanosilica was found to accelerate the hydration process at early ages because of its considerably fine particle size [6]. Positive values are recorded in the literature for systems containing NPs in the existence of MS. Microsilica can display both cement and pozzolanic activity and is very useful in changing the cement paste's early age and hardened age behavior [26]. Through the creation of a micro-level structure supplying for the closure of cracks, the nucleation effect of NPs promotes the hydration response involving the formation of CSH gel. Due to the massive reaction of NPs of silica resulting in early hardening, characteristics such as the setting time are also reduced [27]. In addition to the application methods, the water to cement ratio, the fresh and hardened characteristics depend on the concentration, composition, and particle dimension of the binder and additive particles. It is possible to use NS in powder form or colloidally [28]. Colloidal NS contains amorphous hydroxylated silica NPs with a dimension varying from 1 to $500 \mathrm{~nm}$ in a colloidal suspension form. Colloidal NS particles illustrate less segregation and a nicer dispersity in cement paste and are regarded to promote the development of high-rigidity CSH gel [29]. While studies are available on the single use of MS and NS or combined to alter the behavior of cement paste, there is not much evidence on which one of those parameters is most effective on mechanical properties, such as the compressive strength.

The purpose of this study is to find out the effect of the various ratios of amorphous NS and MS on the compressive strength of cement paste as a function of the water-cement ratio and curing time. In this manner, some mathematical prediction models, including the Linear Relational Model (LR), Nonlinear Model (NLR), Multi-Logistic Model (MLR), and artificial neural network (ANN) are used in two situations of training and testing to evaluate the effect of NS and MS on the compressive strength of cement paste.

Although compressive strength relies on several parameters, it is also sensitive to the mixed proportion, so using more sophisticated model techniques in combination with simplified tools and numerical equations is beneficial for engineers and helps reduce the number of laboratory experiments required. Multivariable models may be regarded as an excellent solution in this respect. The primary advantage of these methods is that they enable the development of alternatives and solutions for linear or nonlinear issues in which mathematical models cannot easily explain the connection between the components [30]. Several models for predicting cement-based materials and multi-linear regression analysis models are widely employed [31,32]. This research aims to develop, characterize, and recommend a multiscale model for predicting the compressive strength of cement paste 
improved with NS and MS. In this respect, the extracted dataset was extensively tested using different modelization approaches to (i) conduct a comparative study and investigate the impact of varying mix formulations, such as NS and MS, as well as the w/c and curing time, on the compressive strength of cement paste adjusted with NS and MS; (ii) using statistical evaluation parameters, test and find the most reliable model to estimate the compressive strength of cement paste adjusted with NS and MS across all models which are linear, nonlinear, multi-logistic, and artificial neural network relation models.

\section{Materials and Methods}

\subsection{Methods}

In total, 205 experimental data from previous publications [33-37] were gathered. The mortar cubes in those publications were determined according to IS 2250-1981, and their size in four papers $[33,34,36,37]$ was $50 \times 50 \times 50 \mathrm{~mm}^{3}$, and in just one of them [35], the model size of $(40 \times 40 \times 40) \mathrm{mm}^{3}$ was used. The criteria for collecting the data was based on compressive strength test, experimental data, and updated credible journals from 2017 to 2020, with studies including cement mortar adjusted by MS and NS without other admixtures and subjected to the same curing conditions. The gathered data were evaluated statistically and randomly assigned to one of two groups. The first group, which was larger, included 150 datasets that were utilized to build the models. The second group included 55 datasets used for testing the models. The summary of the cement paste mixes database is reported in Table 1 . The present objective of the study was to predict which size of silica additives was more effective, the nano-size or micro-size. They were also reported and analyzed statistically. As can be seen from Table 1, the input dataset included nanosilica content (NS, \% of mass of cement), microsilica content (MS, \% of mass of cement), w/c ratio, and curing time ( $\mathrm{t}$, days). The provided dataset, which included many independent characteristics, was utilized to estimate the compressive strength of cement paste modified with NS and MS. Various models were implemented and compared to the actual measured compressive strength (MPa). Figure 1 depicts the flow diagram for the method used in this research. Additionally, the next parts provided and explained the specifics, including data gathering, analysis, modeling, and testing.

Table 1. Summary of different paste mixes modified with nanosilica and microsilica.

\begin{tabular}{|c|c|c|c|c|c|c|}
\hline \multirow[b]{2}{*}{ No. } & \multirow[b]{2}{*}{ Ref. } & \multirow[b]{2}{*}{$\begin{array}{c}\text { w/c } \\
\text { Ratio per Mass }\end{array}$} & \multirow[b]{2}{*}{$\begin{array}{l}\text { Curing Time } \\
\text { (Days) }\end{array}$} & \multicolumn{2}{|c|}{ Additives (\%) } & \multirow[b]{2}{*}{$\begin{array}{c}\text { Compressive } \\
\text { Strength } \\
\text { (MPa) }\end{array}$} \\
\hline & & & & $\begin{array}{l}\text { Nanosilica } \\
\text { (30-100 nm) } \\
\text { (NS) }\end{array}$ & $\begin{array}{c}\text { Microsilica } \\
\text { (0.2 } \mu \mathrm{m}) \\
\text { (MS) }\end{array}$ & \\
\hline 1 & & 0.4 & 3 & 0 & 0 & 15.51 \\
\hline 2 & & 0.4 & 3 & 1.4 & 0 & 16.85 \\
\hline 3 & & 0.4 & 3 & 4.2 & 0 & 23.60 \\
\hline 4 & & 0.4 & 3 & 2.8 & 0 & 21.57 \\
\hline 5 & & 0.4 & 3 & 0 & 4 & 18.88 \\
\hline 6 & & 0.4 & 3 & 2.8 & 4 & 26.97 \\
\hline 7 & & 0.4 & 3 & 4.2 & 4 & 25.62 \\
\hline 8 & & 0.4 & 3 & 1.4 & 4 & 28.31 \\
\hline 9 & & 0.4 & 3 & 4.2 & 9 & 26.29 \\
\hline 10 & & 0.4 & 3 & 0 & 9 & 20.90 \\
\hline 11 & & 0.4 & 3 & 1.4 & 9 & 28.31 \\
\hline 12 & & 0.4 & 3 & 2.8 & 9 & 31.01 \\
\hline 13 & & 0.4 & 3 & 4.2 & 13 & 26.97 \\
\hline 14 & & 0.4 & 3 & 2.8 & 13 & 25.62 \\
\hline 15 & & 0.4 & 3 & 0 & 13 & 23.60 \\
\hline 16 & & 0.4 & 3 & 1.4 & 13 & 24.94 \\
\hline 17 & & 0.4 & 7 & 0 & 0 & 20.90 \\
\hline 18 & & 0.4 & 7 & 1.4 & 0 & 25.62 \\
\hline 19 & & 0.4 & 7 & 4.2 & 0 & 32.36 \\
\hline 20 & & 0.4 & 7 & 2.8 & 0 & 29.66 \\
\hline
\end{tabular}


Table 1. Cont.

\begin{tabular}{|c|c|c|c|c|c|c|}
\hline \multirow[b]{2}{*}{ No. } & \multirow[b]{2}{*}{ Ref. } & \multirow[b]{2}{*}{$\begin{array}{c}\text { w/c } \\
\text { Ratio per Mass }\end{array}$} & \multirow[b]{2}{*}{$\begin{array}{l}\text { Curing Time } \\
\text { (Days) }\end{array}$} & \multicolumn{2}{|c|}{ Additives (\%) } & \multirow[b]{2}{*}{$\begin{array}{c}\text { Compressive } \\
\text { Strength } \\
\text { (MPa) }\end{array}$} \\
\hline & & & & $\begin{array}{l}\text { Nanosilica } \\
(30-100 \mathrm{~nm}) \\
\text { (NS) }\end{array}$ & $\begin{array}{c}\text { Microsilica } \\
(0.2 \mu \mathrm{m}) \\
(\mathrm{MS})\end{array}$ & \\
\hline 21 & & 0.4 & 7 & 1.4 & 4 & 35.73 \\
\hline 22 & & 0.4 & 7 & 0 & 4 & 23.60 \\
\hline 23 & & 0.4 & 7 & 2.8 & 4 & 34.38 \\
\hline 24 & & 0.4 & 7 & 4.2 & 4 & 33.71 \\
\hline 25 & & 0.4 & 7 & 2.8 & 9 & 39.78 \\
\hline 26 & & 0.4 & 7 & 1.4 & 9 & 35.06 \\
\hline 27 & & 0.4 & 7 & 4.2 & 9 & 33.71 \\
\hline 28 & & 0.4 & 7 & 0 & 9 & 26.97 \\
\hline 29 & & 0.4 & 7 & 0 & 13 & 28.31 \\
\hline 30 & & 0.4 & 7 & 1.4 & 13 & 31.69 \\
\hline 31 & & 0.4 & 7 & 4.2 & 13 & 35.73 \\
\hline 32 & & 0.4 & 7 & 2.8 & 13 & 33.71 \\
\hline 33 & & 0.4 & 14 & 0 & 0 & 22.65 \\
\hline 34 & & 0.4 & 14 & 1.4 & 0 & 29.97 \\
\hline 35 & & 0.4 & 14 & 4.2 & 0 & 37.94 \\
\hline 36 & & 0.4 & 14 & 2.8 & 0 & 35.29 \\
\hline 37 & & 0.4 & 14 & 1.4 & 4 & 42.56 \\
\hline 38 & & 0.4 & 14 & 2.8 & 4 & 40.55 \\
\hline 39 & & 0.4 & 14 & 4.2 & 4 & 37.87 \\
\hline 40 & & 0.4 & 14 & 0 & 4 & 31.91 \\
\hline 41 & & 0.4 & 14 & 2.8 & 9 & 43.14 \\
\hline 42 & & 0.4 & 14 & 1.4 & 9 & 39.82 \\
\hline 43 & & 0.4 & 14 & 4.2 & 9 & 38.46 \\
\hline 44 & & 0.4 & 14 & 0 & 9 & 33.83 \\
\hline 45 & & 0.4 & 14 & 4.2 & 13 & 39.72 \\
\hline 46 & & 0.4 & 14 & 2.8 & 13 & 36.40 \\
\hline 47 & & 0.4 & 14 & 0 & 13 & 33.10 \\
\hline 48 & & 0.4 & 14 & 1.4 & 13 & 35.75 \\
\hline 49 & & 0.4 & 21 & 0 & 0 & 26.95 \\
\hline 50 & & 0.4 & 21 & 1.4 & 0 & 36.27 \\
\hline 51 & & 0.4 & 21 & 4.2 & 0 & 40.90 \\
\hline 52 & & 0.4 & 21 & 2.8 & 0 & 39.58 \\
\hline 53 & & 0.4 & 21 & 1.4 & 4 & 46.86 \\
\hline 54 & & 0.4 & 21 & 2.8 & 4 & 45.51 \\
\hline 55 & & 0.4 & 21 & 0 & 4 & 33.54 \\
\hline 56 & & 0.4 & 21 & 4.2 & 4 & 41.50 \\
\hline 57 & & 0.4 & 21 & 2.8 & 9 & 47.43 \\
\hline 58 & & 0.4 & 21 & 1.4 & 9 & 43.45 \\
\hline 59 & & 0.4 & 21 & 0 & 9 & 36.80 \\
\hline 60 & & 0.4 & 21 & 4.2 & 9 & 42.75 \\
\hline 61 & & 0.4 & 21 & 2.8 & 13 & 44.70 \\
\hline 62 & & 0.4 & 21 & 1.4 & 13 & 41.37 \\
\hline 63 & & 0.4 & 21 & 0 & 13 & 38.72 \\
\hline 64 & & 0.4 & 21 & 4.2 & 13 & 46.00 \\
\hline 65 & & 0.4 & 28 & 1.4 & 0 & 29.97 \\
\hline 66 & & 0.4 & 28 & 4.2 & 0 & 37.94 \\
\hline 67 & & 0.4 & 28 & 2.8 & 0 & 35.29 \\
\hline 68 & & 0.4 & 28 & 0 & 4 & 31.91 \\
\hline 69 & & 0.4 & 28 & 4.2 & 4 & 37.87 \\
\hline 70 & & 0.4 & 28 & 1.4 & 4 & 42.56 \\
\hline 71 & & 0.4 & 28 & 2.8 & 4 & 40.55 \\
\hline 72 & & 0.4 & 28 & 4.2 & 9 & 38.46 \\
\hline 73 & & 0.4 & 28 & 1.4 & 9 & 39.82 \\
\hline 74 & & 0.4 & 28 & 2.8 & 9 & 43.14 \\
\hline 75 & & 0.4 & 28 & 0 & 9 & 33.83 \\
\hline
\end{tabular}


Table 1. Cont.

\begin{tabular}{|c|c|c|c|c|c|c|}
\hline \multirow[b]{2}{*}{ No. } & \multirow[b]{2}{*}{ Ref. } & \multirow[b]{2}{*}{$\begin{array}{c}\text { w/c } \\
\text { Ratio per Mass }\end{array}$} & \multirow[b]{2}{*}{$\begin{array}{l}\text { Curing Time } \\
\text { (Days) }\end{array}$} & \multicolumn{2}{|c|}{ Additives (\%) } & \multirow[b]{2}{*}{$\begin{array}{l}\text { Compressive } \\
\text { Strength } \\
\text { (MPa) }\end{array}$} \\
\hline & & & & $\begin{array}{l}\text { Nanosilica } \\
\text { (30-100 nm) } \\
\text { (NS) }\end{array}$ & $\begin{array}{l}\text { Microsilica } \\
(0.2 \mu \mathrm{m}) \\
\text { (MS) }\end{array}$ & \\
\hline 76 & & 0.4 & 28 & 4.2 & 13 & 39.72 \\
\hline 77 & & 0.5 & 3 & 0 & 0 & 26.95 \\
\hline 78 & & 0.5 & 3 & 4.2 & 13 & 42.71 \\
\hline 79 & & 0.5 & 7 & 0 & 0 & 16.47 \\
\hline 80 & & 0.5 & 7 & 1.4 & 0 & 21.76 \\
\hline 81 & & 0.5 & 7 & 4.2 & 0 & 25.88 \\
\hline 82 & & 0.5 & 7 & 2.8 & 0 & 25.29 \\
\hline 83 & & 0.5 & 7 & 1.4 & 4 & 31.76 \\
\hline 84 & & 0.5 & 7 & 0 & 4 & 22.35 \\
\hline 85 & & 0.5 & 7 & 4.2 & 4 & 27.65 \\
\hline 86 & & 0.5 & 7 & 2.8 & 4 & 30.59 \\
\hline 87 & & 0.5 & 7 & 4.2 & 9 & 28.82 \\
\hline 88 & & 0.5 & 7 & 0 & 9 & 23.53 \\
\hline 89 & & 0.5 & 7 & 2.8 & 9 & 33.53 \\
\hline 90 & & 0.5 & 7 & 1.4 & 9 & 30.00 \\
\hline 91 & & 0.5 & 7 & 4.2 & 13 & 30.59 \\
\hline 92 & & 0.5 & 7 & 2.8 & 13 & 29.41 \\
\hline 93 & & 0.5 & 7 & 0 & 13 & 26.47 \\
\hline 94 & & 0.5 & 7 & 1.4 & 13 & 28.24 \\
\hline 95 & & 0.5 & 14 & 0 & 0 & 25.03 \\
\hline 96 & & 0.5 & 14 & 1.4 & 0 & 28.06 \\
\hline 97 & & 0.5 & 14 & 4.2 & 0 & 32.89 \\
\hline 98 & & 0.5 & 14 & 2.8 & 0 & 31.66 \\
\hline 99 & & 0.5 & 14 & 1.4 & 4 & 37.17 \\
\hline 100 & & 0.5 & 14 & 2.8 & 4 & 36.04 \\
\hline 101 & & 0.5 & 14 & 0 & 4 & 27.61 \\
\hline 102 & & 0.5 & 14 & 4.2 & 4 & 34.28 \\
\hline 103 & & 0.5 & 14 & 4.2 & 9 & 34.49 \\
\hline 104 & & 0.5 & 14 & 1.4 & 9 & 34.99 \\
\hline 105 & & 0.5 & 14 & 2.8 & 9 & 38.60 \\
\hline 106 & & 0.5 & 14 & 0 & 9 & 30.20 \\
\hline 107 & & 0.5 & 14 & 1.4 & 13 & 32.81 \\
\hline 108 & & 0.5 & 14 & 4.2 & 13 & 37.06 \\
\hline 109 & & 0.5 & 14 & 2.8 & 13 & 35.84 \\
\hline 110 & & 0.5 & 14 & 0 & 13 & 32.18 \\
\hline 111 & & 0.5 & 21 & 0 & 0 & 25.44 \\
\hline 112 & & 0.5 & 21 & 1.4 & 0 & 32.03 \\
\hline 113 & & 0.5 & 21 & 4.2 & 0 & 36.27 \\
\hline 114 & & 0.5 & 21 & 2.8 & 0 & 35.04 \\
\hline 115 & & 0.5 & 21 & 2.8 & 4 & 40.60 \\
\hline 116 & & 0.5 & 21 & 1.4 & 4 & 41.74 \\
\hline 117 & & 0.5 & 21 & 4.2 & 4 & 37.06 \\
\hline 118 & & 0.5 & 21 & 0 & 4 & 31.58 \\
\hline 119 & & 0.5 & 21 & 4.2 & 9 & 37.85 \\
\hline 120 & & 0.5 & 21 & 1.4 & 9 & 38.97 \\
\hline 121 & & 0.5 & 21 & 2.8 & 9 & 43.19 \\
\hline 122 & & 0.5 & 21 & 0 & 9 & 34.77 \\
\hline 123 & & 0.5 & 21 & 1.4 & 13 & 37.39 \\
\hline 124 & & 0.5 & 21 & 0 & 13 & 35.55 \\
\hline 125 & & 0.5 & 21 & 4.2 & 13 & 41.62 \\
\hline 126 & & 0.5 & 21 & 2.8 & 13 & 40.41 \\
\hline 127 & & 0.5 & 28 & 0 & 0 & 28.57 \\
\hline 128 & & 0.5 & 28 & 1.4 & 0 & 36.31 \\
\hline 129 & & 0.5 & 28 & 4.2 & 0 & 40.48 \\
\hline 130 & & 0.5 & 28 & 2.8 & 0 & 38.69 \\
\hline
\end{tabular}


Table 1. Cont.

\begin{tabular}{|c|c|c|c|c|c|c|}
\hline \multirow[b]{2}{*}{ No. } & \multirow[b]{2}{*}{ Ref. } & \multirow[b]{2}{*}{$\begin{array}{c}\text { w/c } \\
\text { Ratio per Mass }\end{array}$} & \multirow[b]{2}{*}{$\begin{array}{l}\text { Curing Time } \\
\text { (Days) }\end{array}$} & \multicolumn{2}{|c|}{ Additives (\%) } & \multirow[b]{2}{*}{$\begin{array}{l}\text { Compressive } \\
\text { Strength } \\
\text { (MPa) }\end{array}$} \\
\hline & & & & $\begin{array}{l}\text { Nanosilica } \\
\text { (30-100 nm) } \\
\text { (NS) }\end{array}$ & $\begin{array}{l}\text { Microsilica } \\
(0.2 \mu \mathrm{m}) \\
\text { (MS) }\end{array}$ & \\
\hline 131 & & 0.5 & 28 & 1.4 & 4 & 45.24 \\
\hline 132 & & 0.5 & 28 & 2.8 & 4 & 44.05 \\
\hline 133 & & 0.5 & 28 & 4.2 & 4 & 42.26 \\
\hline 134 & & 0.5 & 28 & 0 & 4 & 33.33 \\
\hline 135 & & 0.5 & 28 & 2.8 & 9 & 47.62 \\
\hline 136 & & 0.5 & 28 & 1.4 & 9 & 43.45 \\
\hline 137 & & 0.5 & 28 & 4.2 & 9 & 42.26 \\
\hline 138 & & 0.5 & 28 & 0 & 9 & 37.50 \\
\hline 139 & & 0.5 & 28 & 0 & 13 & 38.69 \\
\hline 140 & & 0.5 & 28 & 4.2 & 13 & 45.24 \\
\hline 141 & & 0.5 & 28 & 1.4 & 13 & 41.67 \\
\hline 142 & & 0.5 & 28 & 2.8 & 13 & 44.05 \\
\hline 143 & \multirow{8}{*}{ [34] } & 0.84 & 3 & 5 & 5 & 15.00 \\
\hline 144 & & 0.84 & 3 & 0 & 5 & 14.00 \\
\hline 145 & & 0.84 & 7 & 0 & 5 & 15.00 \\
\hline 146 & & 0.84 & 7 & 5 & 5 & 17.00 \\
\hline 147 & & 0.84 & 14 & 5 & 5 & 20.00 \\
\hline 148 & & 0.84 & 14 & 0 & 5 & 18.00 \\
\hline 149 & & 0.84 & 28 & 5 & 5 & 24.00 \\
\hline 150 & & 0.84 & 28 & 0 & 5 & 20.00 \\
\hline 151 & \multirow{9}{*}{ [35] } & 0.6 & 7 & 2 & 5 & 34.09 \\
\hline 152 & & 0.6 & 7 & 3 & 5 & 31.79 \\
\hline 153 & & 0.6 & 28 & 1 & 5 & 43.69 \\
\hline 154 & & 0.6 & 28 & 2 & 5 & 44.47 \\
\hline 155 & & 0.6 & 28 & 0 & 5 & 41.04 \\
\hline 156 & & 0.6 & 28 & 3 & 5 & 42.81 \\
\hline 157 & & 0.6 & 90 & 0 & 5 & 50.03 \\
\hline 158 & & 0.6 & 90 & 2 & 5 & 53.68 \\
\hline 159 & & 0.6 & 90 & 1 & 5 & 51.04 \\
\hline 160 & \multirow{14}{*}{ [36] } & 0.4 & 3 & 0 & 0 & 22.80 \\
\hline 161 & & 0.4 & 3 & 2 & 0 & 22.60 \\
\hline 162 & & 0.4 & 3 & 1.5 & 0 & 24.00 \\
\hline 163 & & 0.4 & 3 & 0 & 10 & 19.90 \\
\hline 164 & & 0.4 & 3 & 2 & 10 & 18.80 \\
\hline 165 & & 0.4 & 7 & 2 & 0 & 27.10 \\
\hline 166 & & 0.4 & 7 & 1.5 & 0 & 28.80 \\
\hline 167 & & 0.4 & 7 & 0 & 15 & 25.80 \\
\hline 168 & & 0.4 & 7 & 2 & 10 & 26.10 \\
\hline 169 & & 0.4 & 7 & 0 & 10 & 29.40 \\
\hline 170 & & 0.4 & 28 & 0 & 0 & 34.50 \\
\hline 171 & & 0.4 & 28 & 2 & 0 & 32.50 \\
\hline 172 & & 0.4 & 28 & 1.5 & 0 & 37.90 \\
\hline 173 & & 0.4 & 28 & 0 & 15 & 42.60 \\
\hline 174 & \multirow{10}{*}{ [37] } & 0.5 & 3 & 1 & 0 & 29.21 \\
\hline 175 & & 0.5 & 3 & 2.5 & 0 & 31.31 \\
\hline 176 & & 0.5 & 3 & 2 & 0 & 31.55 \\
\hline 177 & & 0.5 & 3 & 1.5 & 0 & 30.61 \\
\hline 178 & & 0.5 & 3 & 0 & 0 & 25.00 \\
\hline 179 & & 0.5 & 3 & 0 & 30 & 28.27 \\
\hline 180 & & 0.5 & 3 & 2 & 30 & 35.52 \\
\hline 181 & & 0.5 & 3 & 0 & 20 & 27.10 \\
\hline 182 & & 0.5 & 3 & 2 & 20 & 37.16 \\
\hline 183 & & 0.5 & 3 & 2 & 10 & 32.25 \\
\hline
\end{tabular}


Table 1. Cont.

\begin{tabular}{|c|c|c|c|c|c|c|}
\hline \multirow[b]{2}{*}{ No. } & \multirow[b]{2}{*}{ Ref. } & \multirow[b]{2}{*}{$\begin{array}{c}\text { w/c } \\
\text { Ratio per Mass }\end{array}$} & \multirow[b]{2}{*}{$\begin{array}{l}\text { Curing Time } \\
\text { (Days) }\end{array}$} & \multicolumn{2}{|c|}{ Additives (\%) } & \multirow[b]{2}{*}{$\begin{array}{c}\text { Compressive } \\
\text { Strength } \\
\text { (MPa) }\end{array}$} \\
\hline & & & & $\begin{array}{l}\text { Nanosilica } \\
(30-100 \mathrm{~nm}) \\
\text { (NS) }\end{array}$ & $\begin{array}{c}\text { Microsilica } \\
(0.2 \mu \mathrm{m}) \\
(\mathrm{MS})\end{array}$ & \\
\hline 184 & \multirow{22}{*}{ [37] } & 0.5 & 3 & 0 & 10 & 25.70 \\
\hline 185 & & 0.5 & 7 & 0 & 0 & 31.08 \\
\hline 186 & & 0.5 & 7 & 0 & 40 & 35.29 \\
\hline 187 & & 0.5 & 7 & 2 & 40 & 42.07 \\
\hline 188 & & 0.5 & 7 & 2 & 30 & 43.71 \\
\hline 189 & & 0.5 & 7 & 0 & 30 & 36.22 \\
\hline 190 & & 0.5 & 7 & 2 & 20 & 44.18 \\
\hline 191 & & 0.5 & 7 & 0 & 20 & 34.82 \\
\hline 192 & & 0.5 & 7 & 0 & 10 & 33.18 \\
\hline 193 & & 0.5 & 7 & 2 & 10 & 39.26 \\
\hline 194 & & 0.5 & 28 & 1 & 0 & 51.66 \\
\hline 195 & & 0.5 & 28 & 0 & 0 & 44.88 \\
\hline 196 & & 0.5 & 28 & 2.5 & 0 & 54.47 \\
\hline 197 & & 0.5 & 28 & 2 & 0 & 54.70 \\
\hline 198 & & 0.5 & 28 & 2 & 40 & 62.19 \\
\hline 199 & & 0.5 & 28 & 0 & 40 & 52.36 \\
\hline 200 & & 0.5 & 28 & 2 & 30 & 64.06 \\
\hline 201 & & 0.5 & 28 & 0 & 30 & 53.30 \\
\hline 202 & & 0.5 & 28 & 0 & 20 & 51.43 \\
\hline 203 & & 0.5 & 28 & 2 & 20 & 66.87 \\
\hline 204 & & 0.5 & 28 & 2 & 10 & 59.85 \\
\hline 205 & & 0.5 & 28 & 0 & 10 & 48.85 \\
\hline $\begin{array}{l}\text { No. of Data } \\
\quad=205\end{array}$ & & $\begin{array}{c}\text { Ranged between } \\
0.4 \text { and } 0.84\end{array}$ & $\begin{array}{l}\text { Varied between } \\
3 \text { and } 90 \text { Days }\end{array}$ & $\begin{array}{c}\text { Ranged between } \\
0 \text { and } 15 \%\end{array}$ & $\begin{array}{c}\text { Ranged between } \\
0 \text { and } 40 \%\end{array}$ & $\begin{array}{c}\text { Varied } \\
\text { between } \\
14 \text { and } 67 \mathrm{MPa}\end{array}$ \\
\hline
\end{tabular}

\subsection{Statistical Evaluation}

Statistical analysis was performed in the current section to demonstrate the association between input parameters and paste compressive strength. In this respect, all variables considered, including (i) w/c, (ii) curing time, (iii) NS content, and (iv) MS content, were collected and evaluated with compressive strength, and statistical functions such as standard deviation, skewness, kurtosis, and variance were calculated to demonstrate the distribution of each variable with compressive strength. Concerning the kurtosis parameter, the higher negative value shows shorter distribution tails than the normal distribution, whereas the longer tails represent the positive value. About the skewness, the negative value indicates the long left tail, and the positive value is the right tail. Below is ample information on each vector considered as an input parameter:

\section{(i) Water/cement ratio (w/c)}

According to the comprehensive data collected from the previous analyses, the $\mathrm{w} / \mathrm{c}$ of cement paste mixes adjusted with NS and MS varied from 0.4 to 0.84 with a median of 0.5 . Statistical evaluation for the parameters such as variance, standard deviation, skewness, and kurtosis were $0.0119,0.1091,0.2 .082$, and 4.5212, respectively. Additionally, Figure 2a shows a difference between the compressive intensity and the $\mathrm{w} / \mathrm{c}$ ratio- the histogram of modified paste mixtures with NS and MS. Figure $2 \mathrm{~b}$ indicates that, with an improvement in the $\mathrm{w} / \mathrm{c}$ of $0.55 \%$, the compressive strength of the cement paste changed with NS and MS decreased substantially. 


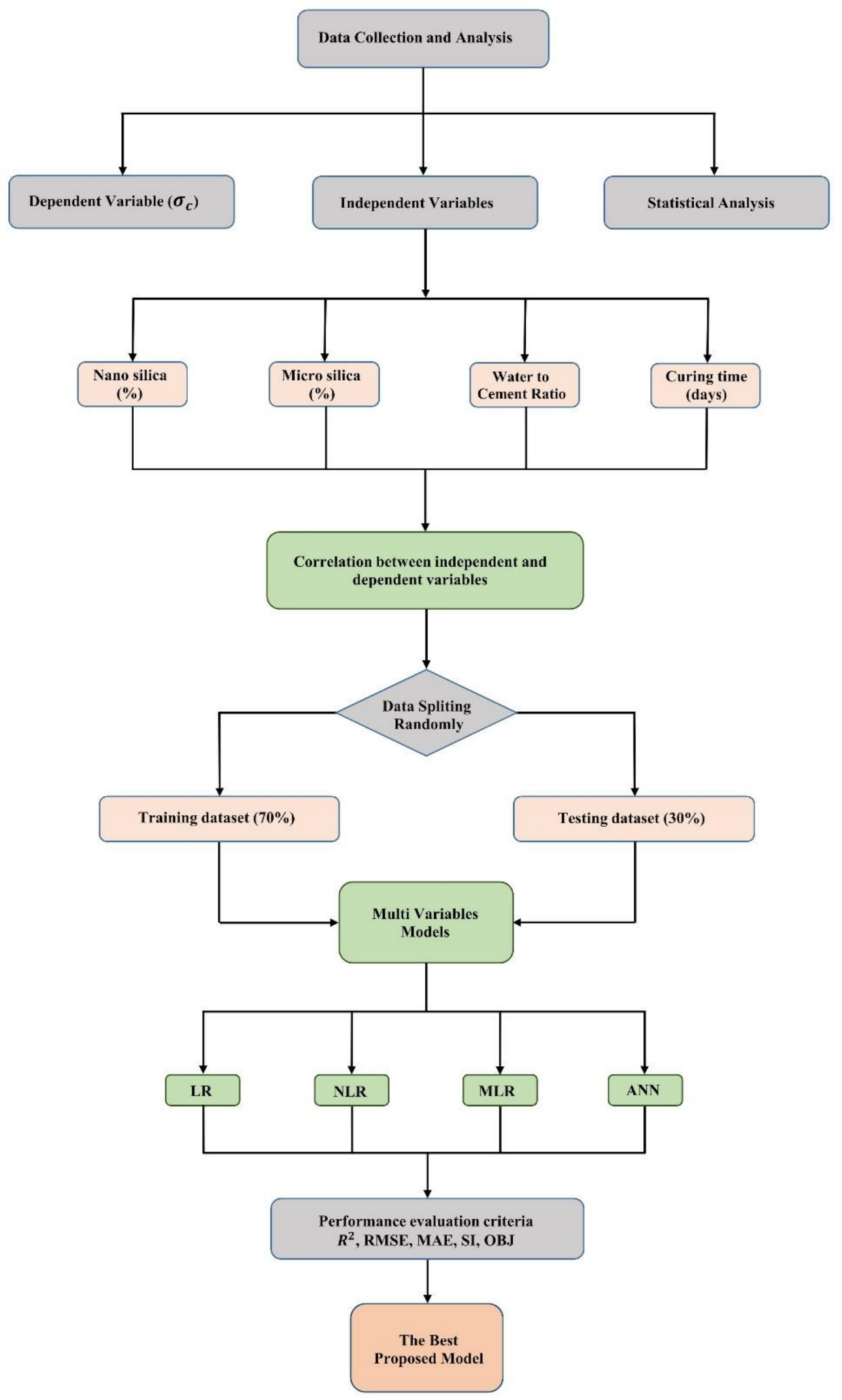

Figure 1. The flowchart followed in this study for cement paste modified with NS and MS. 

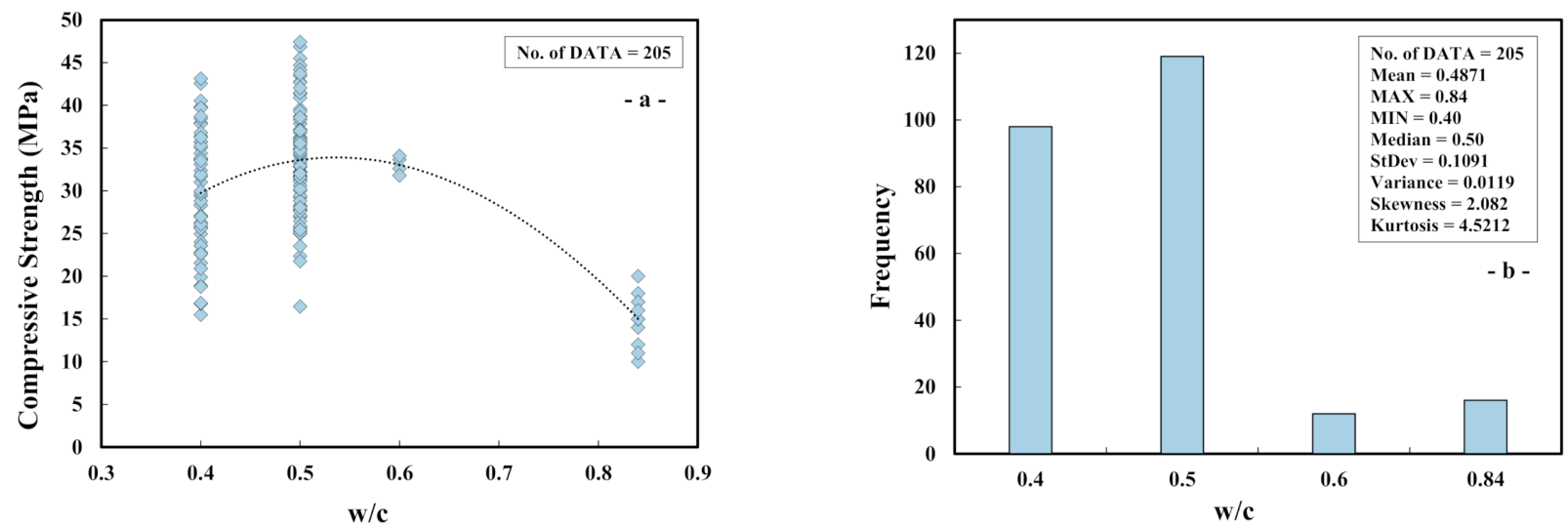

Figure 2. (a) The variation between the compressive strength and w/c and (b) histogram of w/c of cement paste modified with NS and MS.

\section{(ii) Curing time}

To facilitate the hydration procedure, the curing duration should be extended enough to obtain an acceptable early and hardened age compressive strength. Thus, based on the literature data, the curing period range of NS and MS modified paste began from 3 days to 90 days, with a median of 14 days. Based on skewness value, the curing time had a higher value compared to the $\mathrm{w} / \mathrm{c}$ ratio skewness, which was $28.27 \%$. Furthermore, the kurtosis value of curing time was $63.68 \%$ higher than the $\mathrm{w} / \mathrm{c}$ ratio kurtosis. The association between compressive strength and curing time with the NS and MS-altered paste mixture is indicated in Figure 3.
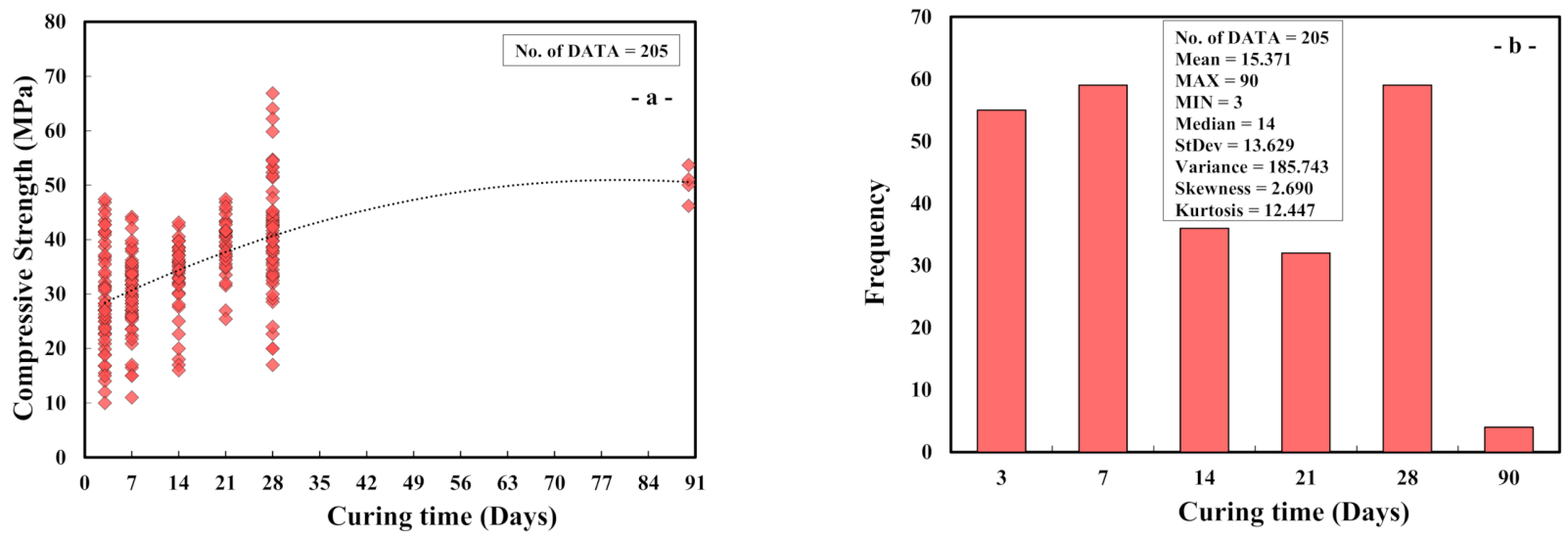

Figure 3. (a) The variation between the compressive strength and curing time and (b) histogram of curing time of cement paste modified with NS and MS.

\section{(iii) NS content}

The NS utilized in the mixing proportions had a particle diameter of less than $50 \mathrm{~nm}$, a surface-to-volume ratio of between 50 and $200 \mathrm{~m}^{2} / \mathrm{g}$, and a purity of more than 99 percent, according to the examination of the gathered dataset from the literature. Between $0 \%$ and $15 \%$ of NS was employed in paste mixes to replace the cement weight, with a median of 1.5 percent. In comparison, the standard deviation, uncertainty, skewness, and kurtosis were 2.47, 6.1, 2.737, and 11.11, respectively. The difference in compressive strength, NS histogram analysis, and histogram analysis are indicated in Figure $4 \mathrm{~b}$. As seen in Figure $4 \mathrm{a}$, there was a weak association between compressive strength and NS content of more than $4 \%$. 

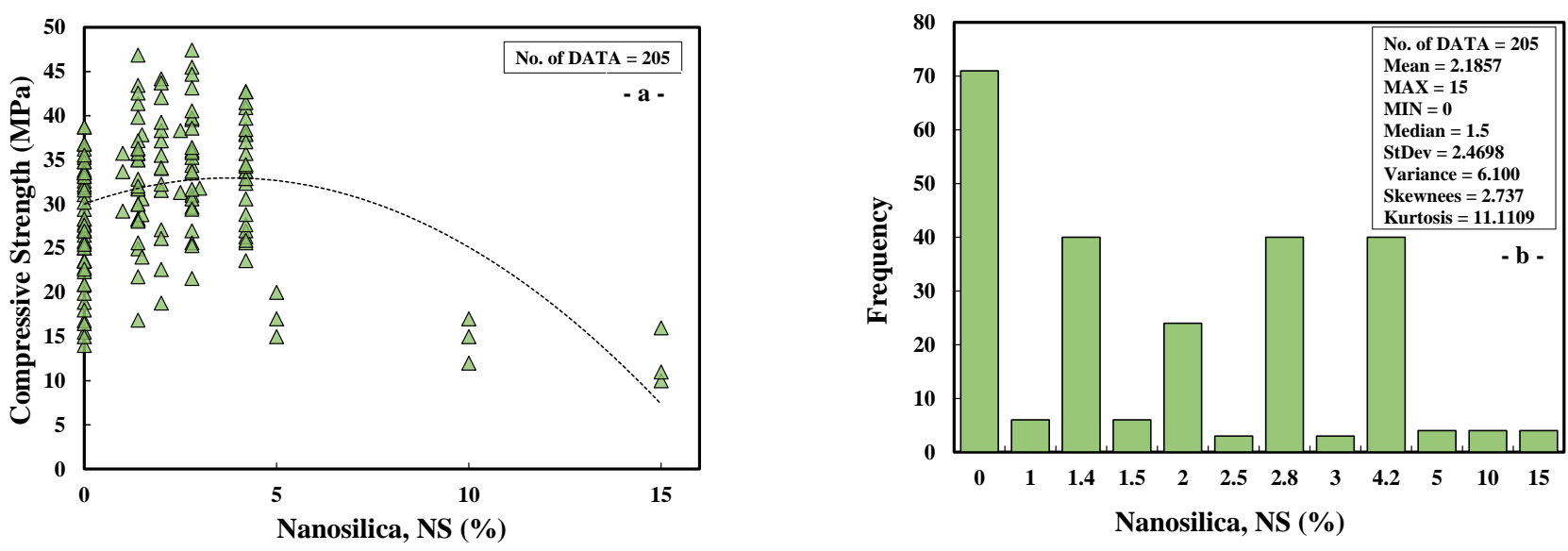

Figure 4. (a) The variation between the compressive strength and nanosilica (NS) and (b) histogram of nanosilica (NS) of cement paste.

\section{(iv) MS content}

The MS utilized in the mix had a particle diameter of less than $50 \mathrm{~nm}$, a surface-tovolume ratio of $10-20 \mathrm{~m}^{2} / \mathrm{g}$, and purity of greater than $99 \%$, according to the dataset derived from the literature. The minimum and maximum proportions of MS used in paste mixtures were between $0 \%$ and $40 \%$, replacing the cement weight with a median of $5 \%$. Based on the Kurtosis value, MS had a lower value than NS, almost $50 \%$. Furthermore, the skewness value of MS was $28 \%$ less than NS skewness. The difference in compressive strength between MS material and the histogram analysis is seen in Figure 5. As indicated in Figure 5a, there was a slowly reducing relationship between compressive strength and MS content of more than $30 \%$.
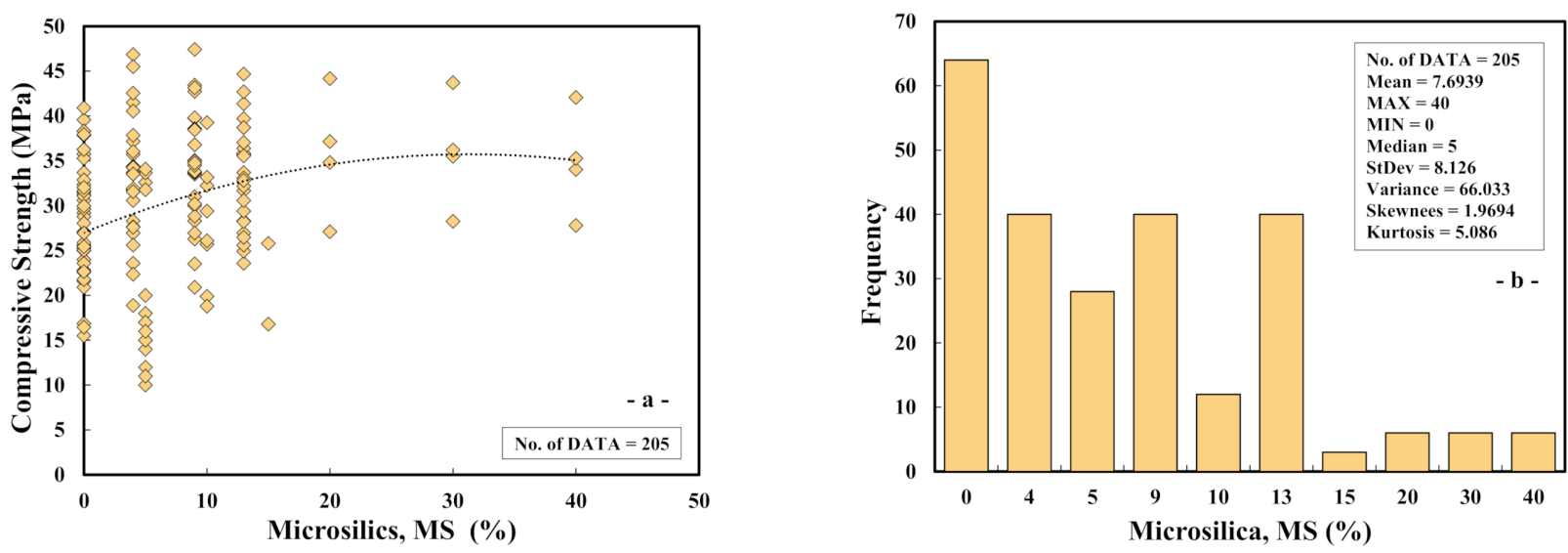

Figure 5. (a) The variation between the compressive strength and microsilica (MS) and (b) histogram of microsilica (MS) of cement paste.

\section{(v) Compressive strength}

The compressive strength of paste mixtures changed with NS and MS varied from 10 to $66.87 \mathrm{MPa}$. A median of $34.76 \mathrm{MPa}$, a standard deviation of $9.80 \mathrm{MPa}$, and a variance of 96.067 MPa were recorded according to the total data recorded in Table 1. From the overall collected results, $73 \%$ had compressive strengths ranging from 10 to $40 \mathrm{MPa}$, and $27 \%$ had compressive strengths ranging from 40 to $66.87 \mathrm{MPa}$ (Table 1 ).

\subsection{Modeling}

Four separate models were suggested to test the effect of the different mixture proportions referred to above on the compressive strength of NS and MS-adjusted cement paste. The proposed models were used in this analysis to estimate the compressive strength of 
cement paste. It needed specific criteria to choose the best model that gave closer estimated results to the measured compressive strength. The following calculation parameters were used to compare the predictions of various models. The most corrected model statistically had a smaller percentage error between the actual and predicted results and had a lower RMSE and SI OBJ and a higher $\mathrm{R}^{2}$.

\subsubsection{Linear Regression Model (LR)}

Linear regression tries to fit the linear equation to the measurable data to predict the relationship between the two variables. The LR model is the most common approach to predicting the compressive strength of concrete [38]. The equation for a linear regression line is Equation (1).

$$
\mathrm{Y}=\mathrm{a}+\mathrm{bX}
$$

$\mathrm{a}$ and $\mathrm{b}$ are the model parameters, $\mathrm{X}$ is the explanatory variable, and $\mathrm{Y}$ is the dependent variable (Equation (1)). Several ingredients and variables that affected paste mixtures' compressive strength adjusted with NS and MS, such as curing time $(t)$, water-cement ratio $(\mathrm{w} / \mathrm{c})$, and other blend proportions, could be included in the equation above. Equation (2) was recommended to incorporate all parameters and quantities that may have affected compressive strength in order to provide more accurate and empirical observations.

$\mathrm{w} / \mathrm{c}$ is the ratio of water to cement, $\mathrm{t}$ is the curing time, NS is the content of nanosilica $(\%)$, and MS is microsilica (\%). In addition, the model parameters are $a, b, c, d$, and e. The suggested Equation (2), since all variables can be adapted linearly, can be used to an extent for Equation (1). While all the different compressive strength variables can influence and interfere with one another, this may not be important in all cases. The model must also constantly be updated to accurately measure the compressive strength $[39,40]$.

$$
\sigma_{\mathrm{c}}=\mathrm{a}(\mathrm{w} / \mathrm{c})+\mathrm{b}(\mathrm{t})+\mathrm{c}(\mathrm{NS})+\mathrm{d}(\mathrm{MS})+\mathrm{e}
$$

\subsubsection{Nonlinear Regression Model (NLR)}

The following Equation (3) can be used to develop a nonlinear regression model in a general form [40-42]. Equation (3) was used to approximate the compressive strength of paste mixtures improved with NS and MS to describe the interrelationship between the various variables in Equations (1) and (2).

$$
\sigma_{\mathrm{c}}=\mathrm{a}(\mathrm{w} / \mathrm{c})^{\mathrm{b}}+\mathrm{c}(\mathrm{t})^{\mathrm{d}}+\mathrm{e}(\mathrm{NS})^{\mathrm{f}}+\mathrm{g}(\mathrm{MS})^{\mathrm{h}}+\mathrm{i}
$$

where $\mathrm{w} / \mathrm{c}$ is the water to cement ratio, $\mathrm{t}$ is the curing time (days), NS is the nanosilica content $(\%)$, and MS is the microsilica content (\%). Furthermore, the model parameters $a, b$, $c, d, e, f, g, h$, and i were determined using the least square method.

\subsubsection{Multi-Logistic Regression Model (MLR)}

The MLR, a regression algorithm, can be used where the predictable variable has a parameter greater than two phases. The MLR is a mathematical method that is close to multiple linear regression. The equation can also find the difference between a predictor variable and the independent variables of Equation (4).

$$
\sigma_{c}=a(w / c)^{b}(t)^{C}(N S)^{d}(M S)^{e}
$$

Equation (14) has a drawback in that it cannot be used to estimate the compressive strength of paste without the presence of NS and MS. As a result, the NS and MS content in this model should be larger than zero (the constraint of Equation (4) is NS and MS content $>0 \%$ ). The least-square approach was also used to find the parameters of the models a, b, c, d, and e and model variables. 


\subsubsection{Artificial Neural Network Model (ANN)}

A multilayer perceptron is a neural network connecting multiple layers in a directed graph, which means that the signal path through the nodes only goes one way. Apart from the input nodes, each node has a nonlinear activation function. Since there are multiple layers of neurons, ANN is a deep learning technique. ANN is widely used to solve computational neuroscience and parallel distributed processing research problems. The multilayer perceptron is an ANN feedforward class. The ANN procedure consists of three main parts: the input layer (variables), hidden layers (neurons and additional layers), and the output layer (desired output result). In this study, the main input variables of Equations (5) and (6) involved water-cement ratio, curing days, and additives (nanosilica and microsilica).

$$
\begin{gathered}
\beta_{n}=a_{n}(w / c)+b_{n}(t)+c_{n}(N S)+d_{n}(M S)+e_{n} \\
\sigma_{c}=\frac{\text { Node }_{1}}{1+e^{-\beta 1}}+\frac{\text { Node }_{2}}{1+e^{-\beta 2}}+\ldots+\frac{\text { Node }_{n}}{1+e^{-\beta n}}+\text { Treshold }
\end{gathered}
$$

where $\mathrm{w} / \mathrm{c}$ is the water to cement ratio (\%), $\mathrm{t}$ is the curing time (days), NS is the nanosilica content (\%), and MS is the microsilica content (\%). All the $\beta$ values that depend on the mentioned values by linear Equations (5) and (6) directly given by the neural learning machine (Weka), $\mathrm{n}$ is several neurons that are defined with the best of trial and error by the same machine which provides the most value of $R^{2}$. Furthermore, node ${ }_{1}$, node $_{2} \ldots$ node $_{\mathrm{n}}$, and all the other model parameters $\mathrm{a}, \mathrm{b}, \mathrm{c}, \mathrm{d}$, e, and threshold could be determined by WEKA software directly with the same trial effort.

\subsubsection{Criteria for Evaluation of Models}

Various output parameters, including the coefficient of determination $\left(\mathrm{R}^{2}\right)$, Root Mean Squared Error (RMSE), Mean Absolute Error (MAE), Scatter Index (SI), and OBJ, which were specified, were used to test and evaluate the efficiency of the proposed models.

$$
\begin{gathered}
\mathrm{R}^{2}=\left(\frac{\sum_{\mathrm{p}=1}^{\mathrm{p}}\left(\mathrm{t}_{\mathrm{p}}-\mathrm{t}^{\prime}\right)\left(\mathrm{y}_{\mathrm{p}}-\mathrm{y}^{\prime}\right)}{\sqrt{\left[\sum_{\mathrm{p}=1}^{\mathrm{p}}\left(\mathrm{t}_{\mathrm{p}}-\mathrm{t}^{\prime}\right)^{2}\right]\left[\sum_{\mathrm{p}=1}^{\mathrm{p}}\left(\mathrm{y}_{\mathrm{p}}-\mathrm{y}^{\prime}\right)^{2}\right]}}\right)^{2} \\
\mathrm{RMSE}=\sqrt{\frac{\sum_{\mathrm{p}=1}^{\mathrm{p}}\left(\mathrm{y}_{\mathrm{p}}-\mathrm{t}_{\mathrm{p}}\right)^{2}}{\mathrm{p}}} \\
\mathrm{MAE}=\frac{\sum_{\mathrm{p}=1}^{\mathrm{p}}\left|\left(\mathrm{y}_{\mathrm{p}}-\mathrm{t}_{\mathrm{p}}\right)\right|}{\mathrm{p}} \\
\text { OBJ }=\left(\frac{\mathrm{n}_{\mathrm{tr}}}{\mathrm{n}_{\mathrm{all}}} * \frac{\mathrm{RMSE}_{\mathrm{tr}}+\mathrm{MAE}_{\mathrm{tr}}}{\mathrm{t}^{\prime}}\right)+\left(\frac{\mathrm{n}_{\mathrm{tst}}}{\mathrm{n}_{\mathrm{tal}}} * \frac{\text { RMSE }_{\text {tst }}+\mathrm{MAE}_{\text {tst }}}{\mathrm{R}_{\mathrm{tst}}^{2}+1}\right)
\end{gathered}
$$

where $y_{p}$ and $t_{p}$ are the predicted and measured values of the path trend, correspondingly, and $\mathrm{t}^{\prime}$ and $\mathrm{y}^{\prime}$ are the averages of the measured and predicted values, respectively. $\mathrm{n}$ is the number of trends (collected data) in the relevant dataset, and $\mathrm{tr}_{\mathrm{r}}$ tst and all are the training, testing, and all datasets, respectively.

However, for the $R^{2}$ value, the closer the numerical value of $R^{2}$ to the value of 1 , the stronger and more accurate the obtained model. When it came to the SI parameter, a model had poor performance when it was $>0.3$, fair performance when it was 0.2 SI 0.3 , good performance when it was $0.1 \mathrm{SI} 0.2$, and excellent performance when it was $<0.1[38,43]$. 
Moreover, the OBJ function was used as a critical output parameter in Equation (11) to determine the utility of the proposed models.

\subsubsection{Sensitivity of Parameters}

In order to understand the magnitude of the effect of each parameter on the compressive strength in the selected superior model, the following proposed method was used. Each time one of the parameters was removed from the superior model, values were obtained for each of the three criteria such as $\mathrm{R}^{2}$, RMSE, and MAE. Finally, by comparing the results, the most change would mean the highest sensitivity of the ordering parameter. In the case of $R^{2}$, the lower value and, in the case of RMSE and MAE, the highest value would represent the most effective parameter.

\section{Results}

\subsection{Predicted and Measured Compressive Strength Relationships}

\subsubsection{The LR Model}

Figure 6 displays the relationship between the expected and real compressive strength of paste mixtures adjusted with NS and MS for training and testing datasets, respectively. According to the model parameters, the $\mathrm{w} / \mathrm{c}$ ratio and NS material had a major effect on the compressive strength of the paste adjusted with NS and MS. The weight of each parameter on the compressive strength of paste adjusted with NS and MS was calculated for the current model by the least square approach in Excel [44,45]. The equation for the LR model could be written as follows for various weight parameters (Equation (12)).

$$
\sigma_{\mathrm{c}}=-22.17 \mathrm{w} / \mathrm{c}+0.5 \mathrm{t}+1.32 \mathrm{NS}+0.47 \mathrm{MS}+31.23
$$
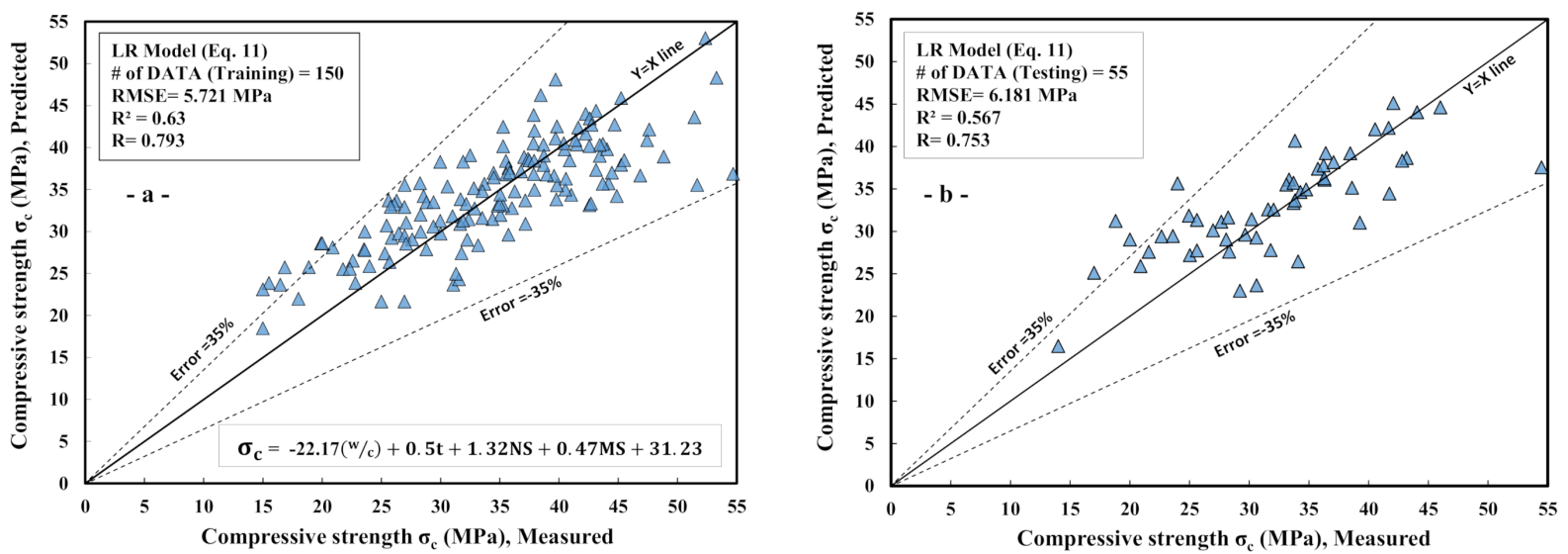

Figure 6. Comparison between the measured and predicted compressive strength of cement paste with nanosilica (NS) and microsilica (MS) using Linear Regression model (LR). (a) Training dataset and (b) testing dataset.

As can be seen from the equation above, the $\mathrm{w} / \mathrm{c}$ ratio had the greatest effect on the compressive strength reduction in all factors. This may correspond to the experimental findings reported in the literature [46,47]. The assessment parameters for this model, such as the $\mathrm{R}^{2}$, MAE, and RMSE, were $0.63,4.44 \mathrm{MPa}$, and $5.72 \mathrm{MPa}$, respectively. Moreover, the $\mathrm{OBJ}$ and SI values for the current model were 4.56 and 0.16 for the training dataset.

\subsubsection{NLR Model}

Figure 7 displays the actual compressive strength versus the predicted compressive strength based on experimental studies of paste mixtures altered with NS and MS for training and testing datasets accordingly. This model showed that the $\mathrm{w} / \mathrm{c}$ ratio was the most significant parameter that influenced the compressive strength of the paste mixtures. Several previous experiments demonstrated this, in which decreases in the w/c ratio 
substantially increased the compressive strength of the cement paste mixtures $[6,7,48,49]$. The following is the suggested equation for the NLR model with various vector parameters (Equation (13)).

$$
\sigma \mathrm{c}=35(\mathrm{w} / \mathrm{c})^{-0.176}+8.635 \mathrm{t}^{0.37}+4.65 \mathrm{NS}^{0.2}+0.33 \mathrm{MS}^{1.1}-35
$$
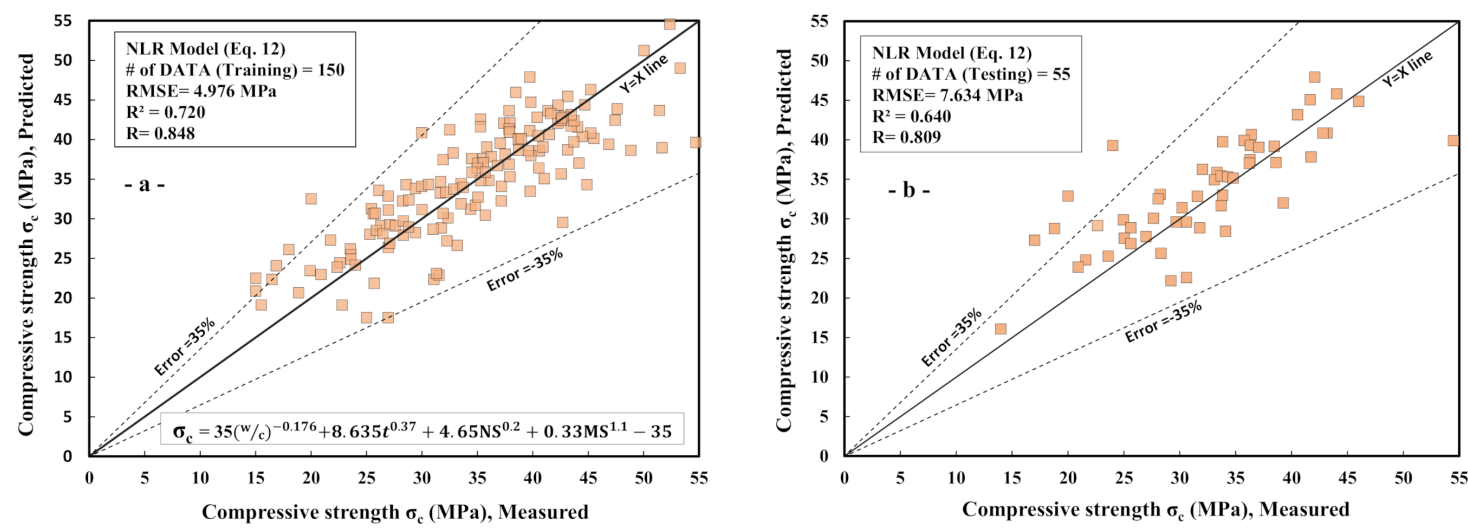

Figure 7. Comparison between the measured and predicted compressive strength of cement paste with nanosilica (NS) and microsilica (MS) using Non-Linear Regression model (NLR). (a) Training dataset and (b) testing dataset.

The $\mathrm{R}^{2}$, RMSE, and MAE evaluation parameters for this model were $0.72,4.98 \mathrm{MPa}$, and $3.81 \mathrm{MPa}$. Furthermore, the current OBJ of the model and SI values for the training dataset were 3.74 and 0.14 , respectively.

\subsubsection{Multi-Logistic Regression Model (MLR)}

Figure 8 demonstrates the relationship between the expected compressive strength versus the actual compressive strength based on experimental studies with paste mixtures adjusted with NS and MS for training and testing datasets, collectively. The curing time was the most effective aspect that influenced the paste mixtures' compressive strength adjusted with NS and MS compared to other models. Additionally, among additives, the effect of NS was greater than MS. Equation (14) reflects the established model for the MLR model with different control factors.

$$
\sigma \mathrm{c}=18.73(\mathrm{w} / \mathrm{c})^{-0.121} \mathrm{t}^{0.227} \mathrm{NS}^{0.011} \mathrm{MS}^{0.008}
$$
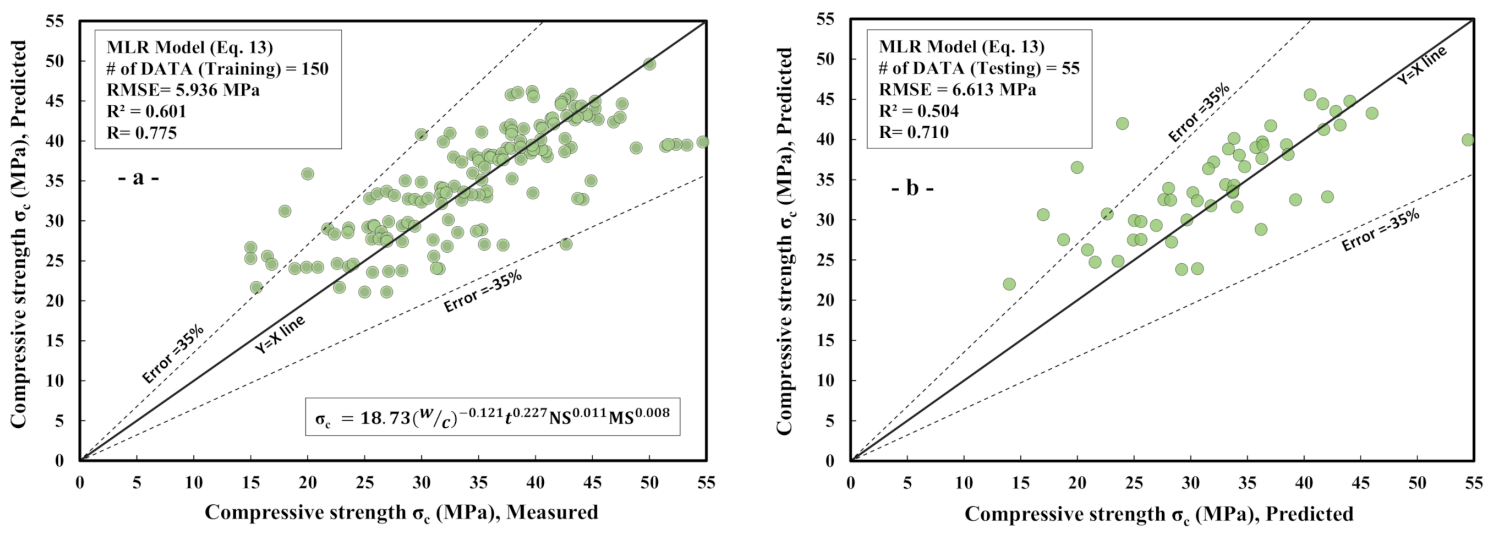

Figure 8. Comparison between the measured and predicted compressive strength of Cement paste with nanosilica (NS) and microsilica (MS) using Multi-Linear regression model (MLR). (a) Training dataset and (b) testing dataset. 
The $\mathrm{R}^{2}$, RMSE, and MAE evaluation parameters for this model were 0.60, 5.94 MPa, and $4.35 \mathrm{MPa}$. Furthermore, the current OBJ of the model and SI values for the training dataset were 4.70 and 0.169 , respectively.

\subsubsection{Artificial Neural Network Model (ANN)}

Figure 9 displays the predicted compressive strength versus actual compressive strength based on experimental studies of paste mixtures altered with NS and MS for training and testing datasets accordingly. As shown by this model on the basis of Figure 10, the curing time was the most significant parameter that influenced the compressive strength of the paste mixtures. The following (Equations (15) and (16)) are the suggested equations for the ANN model based on Equations (15) and (6) with various vector parameters obtained by WEKA machine learning algorithms. These parameters were collected in Table 2 and applied to the following matrix (Equation (15)) to obtain the value of $\beta 1-\beta 14$. It should be noted that through the 28 trials conducted in WEKA with various numbers of hidden layers and neurons (Table 3), the case with 2 hidden layers and 21 neurons $(14,7)$ was the best one with the highest $\mathrm{R}^{2}$ value and the lowest amount of RMSE and MAE compared to another, but due to equation complexity, the case with 1 hidden layer and 14 neurons was chosen, which had the best conditions through the one-layer trials (Figures 11 and 12).
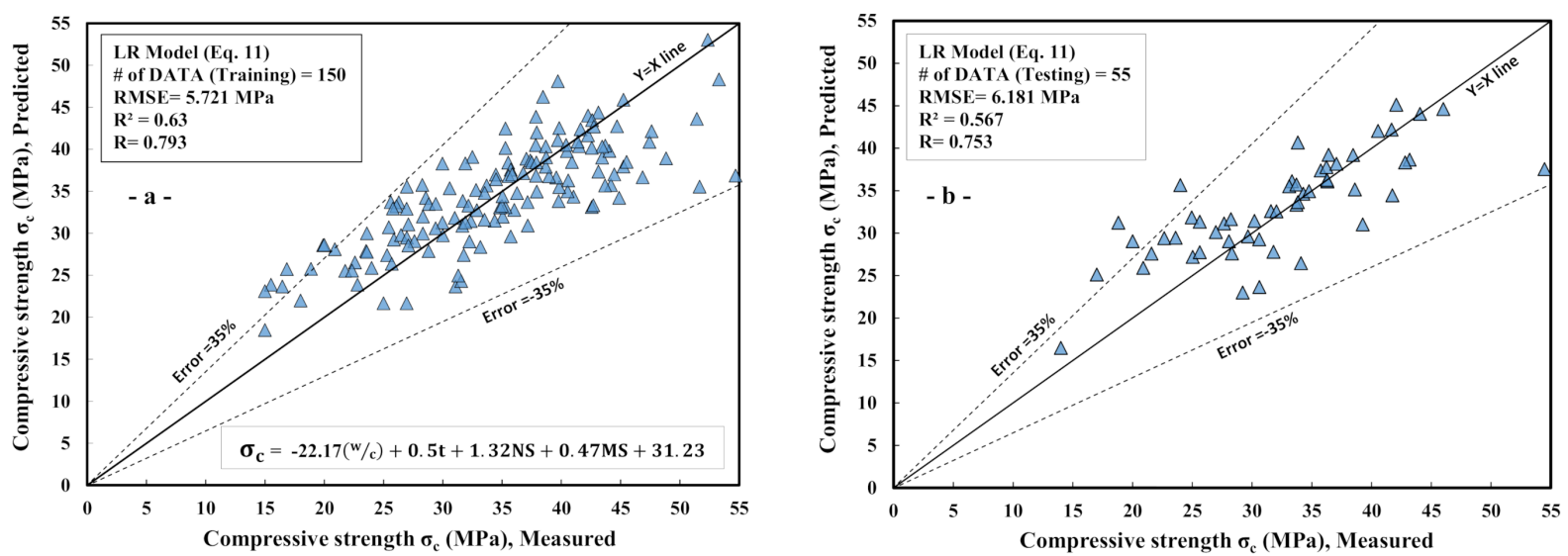

Figure 9. Comparison between the measured and predicted compressive strength of cement paste with nanosilica (NS) and microsilica (MS) using Linear Regression model (LR). (a) Training dat taset and (b) testing dataset.

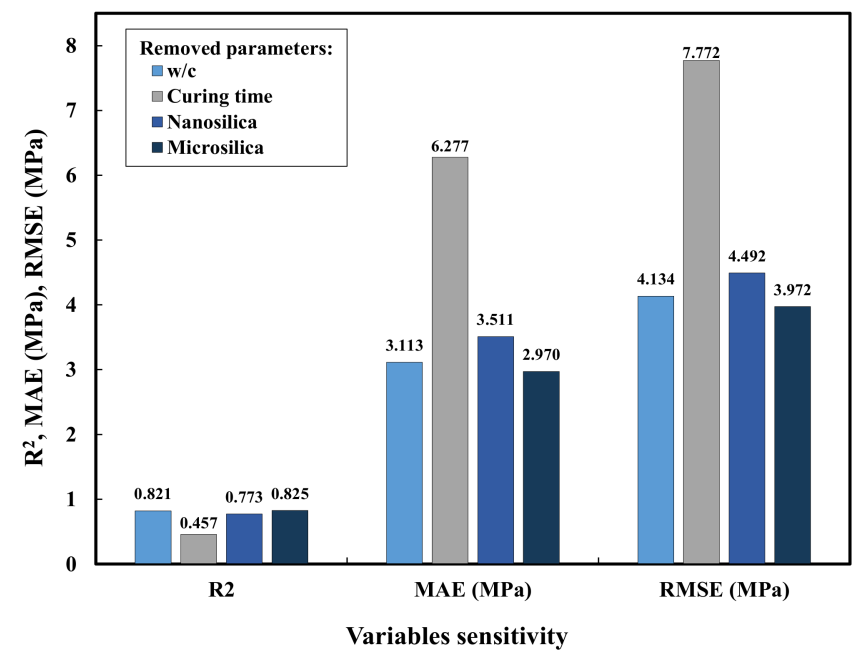

Figure 10. Sensitivity comparison of the variables on the compressive strength of cement paste with nanosilica (NS) and microsilica (MS) using ANN model. 
Table 2. The parameters for compressive strength using the ANN model based on trial no.14 in Table 2 and using them in (Equations (15) and (16))

\begin{tabular}{|c|c|c|c|c|c|c|c|c|c|c|c|c|c|c|c|}
\hline & $\begin{array}{l}\text { LM } \\
\text { No: }\end{array}$ & 1 & 2 & 3 & 4 & 5 & 6 & 7 & 8 & 9 & 10 & 11 & 12 & 13 & 14 \\
\hline \multirow{5}{*}{$\begin{array}{c}\text { Model } \\
\text { Pa- } \\
\text { ram- } \\
\text { eters }\end{array}$} & a & 1.71 & -6.42 & 0.08 & 6.84 & 0.28 & 4.02 & 5.35 & -16.8 & 5.89 & -2.73 & 10.73 & 4.25 & 5.83 & 2.08 \\
\hline & b & 6.88 & 7.41 & 2.46 & 3.47 & 12.64 & -1.56 & -6.63 & -2.13 & 2.27 & 7.26 & -1.29 & -0.26 & -2.86 & 1.70 \\
\hline & c & -10.2 & 0.98 & -4.43 & 6.14 & -4.81 & 5.09 & -3.40 & -1.08 & 14.48 & -0.58 & -1.64 & 0.97 & 7.04 & 3.92 \\
\hline & d & 4.83 & -0.67 & -0.83 & -2.05 & -2.78 & 6.71 & 4.56 & 8.22 & -4.98 & 3.00 & 1.33 & 0.03 & 6.22 & -2.30 \\
\hline & e & -3.28 & 0.07 & -5.60 & 5.85 & -3.14 & 0.87 & -6.99 & -10.6 & -7.96 & 2.13 & 6.91 & -2.37 & 1.56 & -2.58 \\
\hline \multicolumn{2}{|c|}{ Nodes } & 0.80 & 1.58 & -3.90 & 0.75 & 1.99 & 2.08 & -1.79 & 0.73 & 3.28 & -0.73 & 1.46 & 0.86 & -1.64 & -5.93 \\
\hline \multicolumn{2}{|c|}{ Threshold } & \multicolumn{14}{|c|}{-1.75} \\
\hline
\end{tabular}

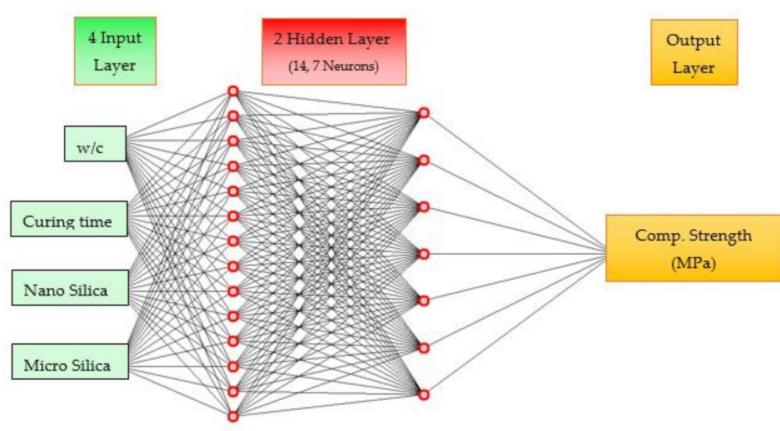

(a)

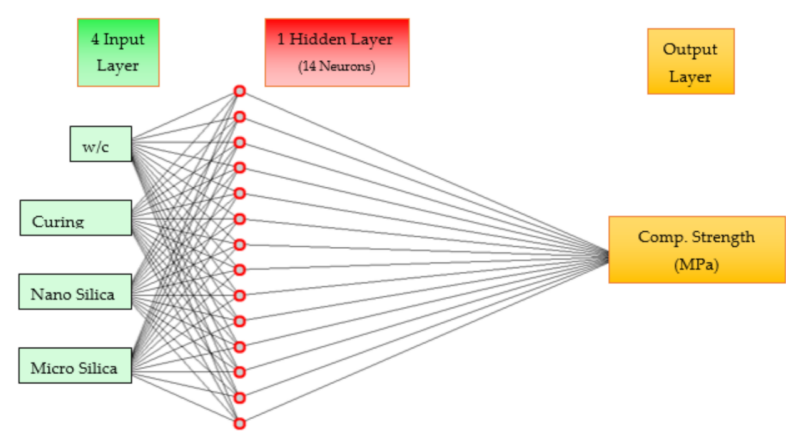

(b)

Figure 11. The Optimal Architecture of Neural Network Model; (a) 14 and 7 neurons; (b) 14 neurons.

$$
\sigma_{c}=\frac{0.8}{1+\mathrm{e}^{-\beta 1}}+\frac{1.58}{1+\mathrm{e}^{-\beta 2}}+\ldots+\frac{-5.93}{1+\mathrm{e}^{-\beta 14}}-1.75
$$

The $\mathrm{R}^{2}$, RMSE, and MAE evaluation parameters for this model were $0.899,3.01 \mathrm{MPa}$, and $2.19 \mathrm{MPa}$, respectively. Furthermore, the current OBJ of the model and SI values for the training dataset were 2.00 and 0.09 , respectively.

$$
\left[\begin{array}{ccccc}
1.71 & 6.88 & -10.2 & 4.83 & -3.28 \\
-6.42 & 7.41 & 0.98 & -0.67 & 0.08 \\
0.08 & 2.46 & -4.43 & -0.83 & -5.6 \\
6.84 & 3.47 & 6.14 & -2.05 & 5.85 \\
0.28 & 12.64 & -4.81 & -2.78 & -3.14 \\
4.02 & -1.56 & 5.09 & 6.71 & 0.87 \\
5.35 & -6.63 & -3.4 & 4.56 & -6.99 \\
-16.8 & -2.13 & -1.08 & 8.22 & -10.6 \\
5.89 & 2.27 & 14.48 & -4.98 & -7.96 \\
-2.73 & 7.26 & -0.58 & 3 & 2.13 \\
10.73 & -1.29 & -1.64 & 1.33 & 6.91 \\
4.25 & -0.26 & 0.97 & 0.03 & -2.37 \\
5.83 & -2.86 & 7.04 & 6.22 & 1.56 \\
2.08 & 1.7 & 3.92 & -2.3 & -2.58
\end{array}\right] *\left[\begin{array}{c}
\frac{w}{c} \\
t \\
N S \\
M S \\
1
\end{array}\right]=\left[\begin{array}{c}
\beta_{1} \\
\beta_{2} \\
\beta_{3} \\
\beta_{4} \\
\beta_{5} \\
\beta_{6} \\
\beta_{7} \\
\beta_{8} \\
\beta_{8} \\
\beta_{10} \\
\beta_{11} \\
\beta_{12} \\
\beta_{13} \\
\beta_{14}
\end{array}\right]
$$


Table 3. Choosing the best-hidden layer and neurons for the ANN model.

\begin{tabular}{|c|c|c|c|c|c|}
\hline $\begin{array}{c}\text { \# of } \\
\text { Layers }\end{array}$ & \# of Neuron & $\begin{array}{c}\text { \# of Neurons } \\
\text { for Each Layer * }\end{array}$ & $\mathbf{R} * *$ & $\begin{array}{l}\text { MAE } \\
\text { (MPa) }\end{array}$ & $\begin{array}{l}\text { RMSE } \\
\text { (MPa) }\end{array}$ \\
\hline 1 & 2 & 2 & 0.862 & 4.019 & 5.048 \\
\hline 1 & 3 & 3 & 0.883 & 3.729 & 4.675 \\
\hline 1 & 4 & 4 & 0.897 & 3.467 & 4.416 \\
\hline 1 & 5 & 5 & 0.921 & 3.1 & 3.908 \\
\hline 1 & 6 & 6 & 0.928 & 2.715 & 3.552 \\
\hline 1 & 7 & 7 & 0.929 & 2.623 & 3.515 \\
\hline 1 & 8 & 8 & 0.94 & 2.452 & 3.29 \\
\hline 1 & 9 & 9 & 0.937 & 2.54 & 3.299 \\
\hline 1 & 10 & 10 & 0.943 & 2.395 & 3.149 \\
\hline 1 & 12 & 12 & 0.945 & 2.392 & 3.14 \\
\hline 1 & 14 & 14 & 0.948 & 2.19 & 3.005 \\
\hline 1 & 15 & 15 & 0.944 & 2.443 & 3.122 \\
\hline 2 & 4 & $2+2$ & 0.857 & 3.862 & 4.869 \\
\hline 2 & 6 & $2+4$ & 0.857 & 3.851 & 4.863 \\
\hline 2 & 8 & $4+4$ & 0.901 & 3.286 & 4.202 \\
\hline 2 & 12 & $4+8$ & 0.942 & 2.383 & 3.158 \\
\hline 2 & 14 & $6+8$ & 0.95 & 2.143 & 2.936 \\
\hline 2 & 15 & $6+9$ & 0.931 & 2.557 & 3.422 \\
\hline 2 & 16 & $6+10$ & 0.939 & 2.436 & 3.269 \\
\hline 2 & 16 & $2+14$ & 0.889 & 3.46 & 4.317 \\
\hline 2 & 15 & $5+10$ & 0.932 & 2.612 & 3.408 \\
\hline 2 & 12 & $8+4$ & 0.956 & 2.048 & 2.771 \\
\hline 2 & 16 & $8+8$ & 0.962 & 1.815 & 2.552 \\
\hline 2 & 18 & $9+9$ & 0.964 & 1.863 & 2.58 \\
\hline 2 & 18 & $12+6$ & 0.961 & 1.878 & 2.627 \\
\hline 2 & 21 & $14+7$ & 0.977 & 1.392 & 2.1 \\
\hline 3 & 12 & $2+4+6$ & 0.857 & 3.857 & 4.865 \\
\hline 3 & 18 & $3+6+9$ & 0.92 & 2.883 & 3.702 \\
\hline
\end{tabular}

* For example, $2+4$ indicates that there are 2 neurons in the first layer and 4 neurons in the second layer. ${ }^{*} \mathrm{R}$ is the correlation coefficient which the square of that is coefficient of determination $\left(\mathrm{R}^{2}\right)$.

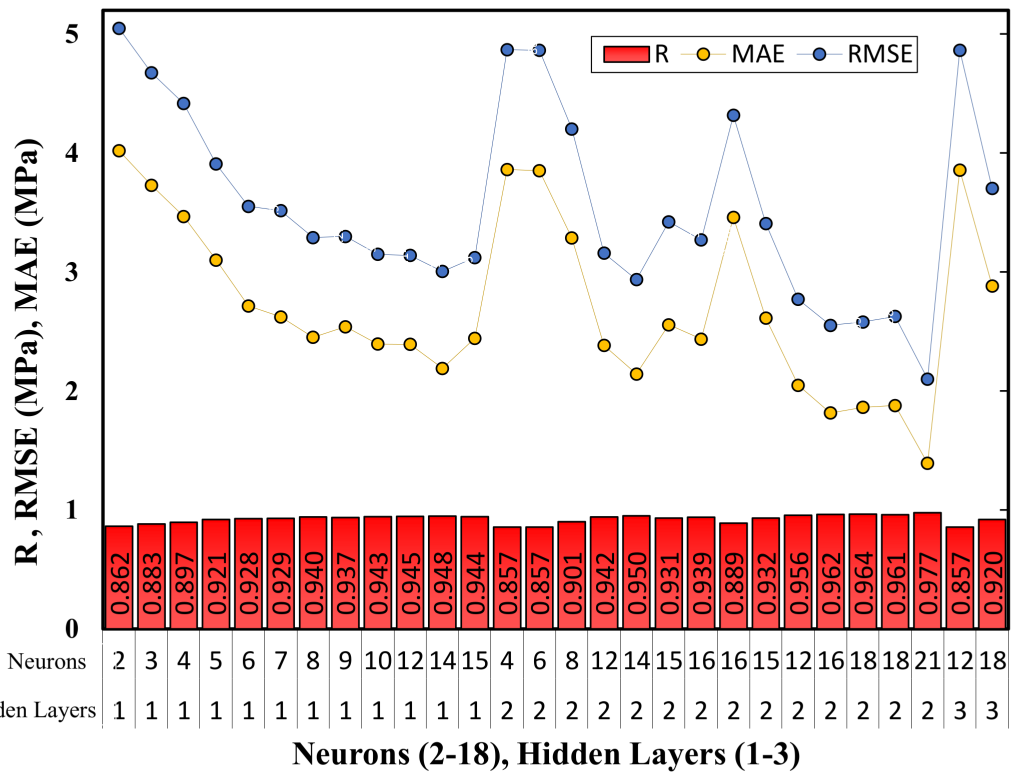

Figure 12. Statistical assessments to evaluate the artificial neural network model using a training dataset.

\subsubsection{Comparison between Developed Models}

As stated earlier, five distinct statistical techniques were used to evaluate the suggested models' efficiency: RMSE, SI MAE, $\mathrm{R}^{2}$, and OBJ. The ANN model had a higher $\mathrm{R}^{2}$ with 
lower RMSE and MAE values among the four different models compared to the LR, NLR, and MLR models (Figure 13). Additionally, Figure 14 presents the SI and OBJ together to compare the model estimations of the compressive strength of paste mixes using training and testing data. At a glance, the ANN model was the best one of the prediction models, with the lowest scatter index $(<0.1$-excellent performance) and the shortest bars for OBJ parameters in both training and testing. Moreover, Figures 15 and 16 affirm that the ANN model had the lowest oscillation range of residual error compared to other models. All the mentioned figures showed that the predicted and measured values of compressive strength were more closed for the ANN model, indicating the superior performance of the ANN model compared to other models.

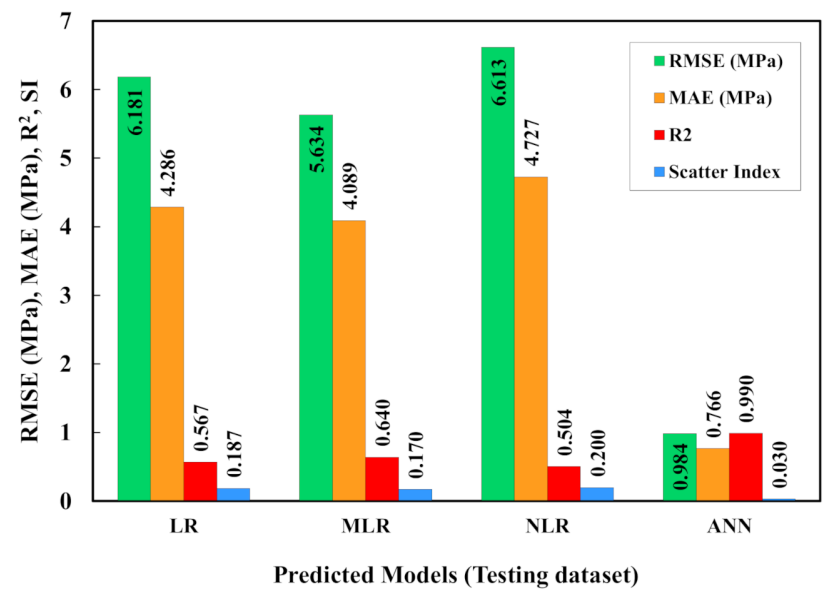

(a)

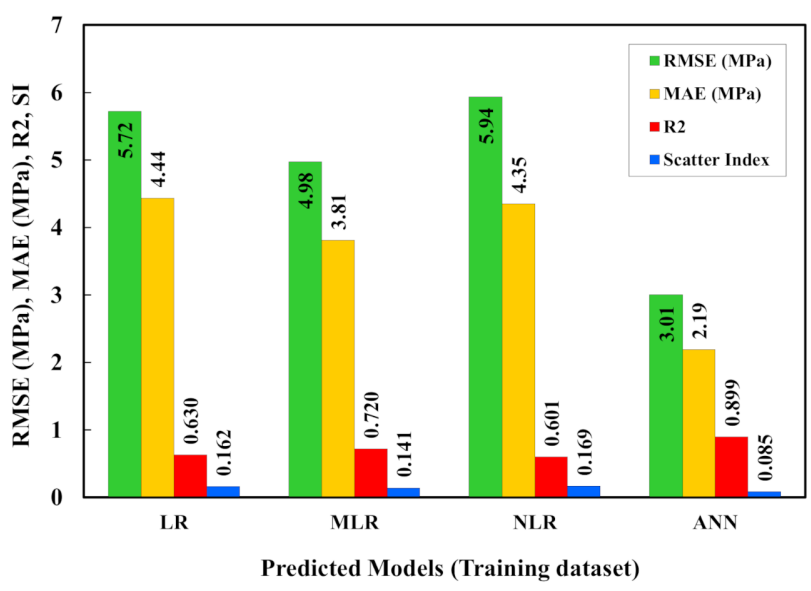

(b)

Figure 13. Statistical assessments to evaluate the efficiency of models used in this study. (a) Training dataset and (b) testing dataset.

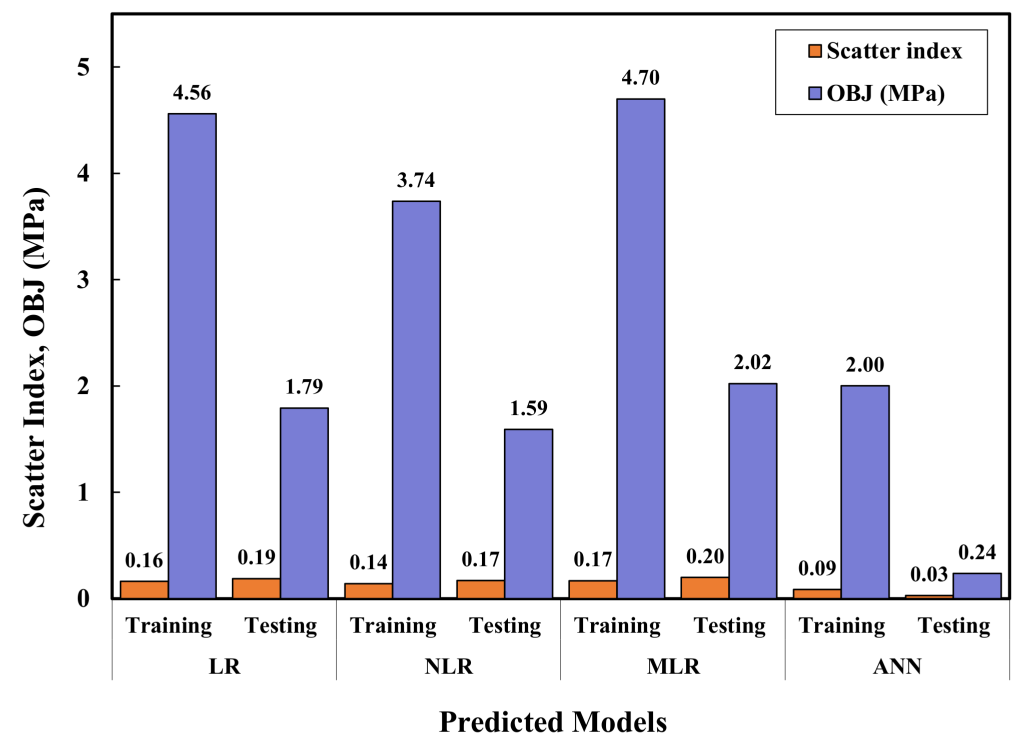

Figure 14. Superposition of measured and predicted value comparison between predicted models.

The OBJ value of training and testing for all proposed models is given in Figure 14 separately. The total OBJ (total of training and testing objective) values for LR, NLR, MLR, and ANN were 6.35, 5.33, 6.72, and 2.24, respectively, which also demonstrated overall that the ANN model was more efficient regarding the estimation of the compressive strength of paste mixtures modified with NS and MS. 


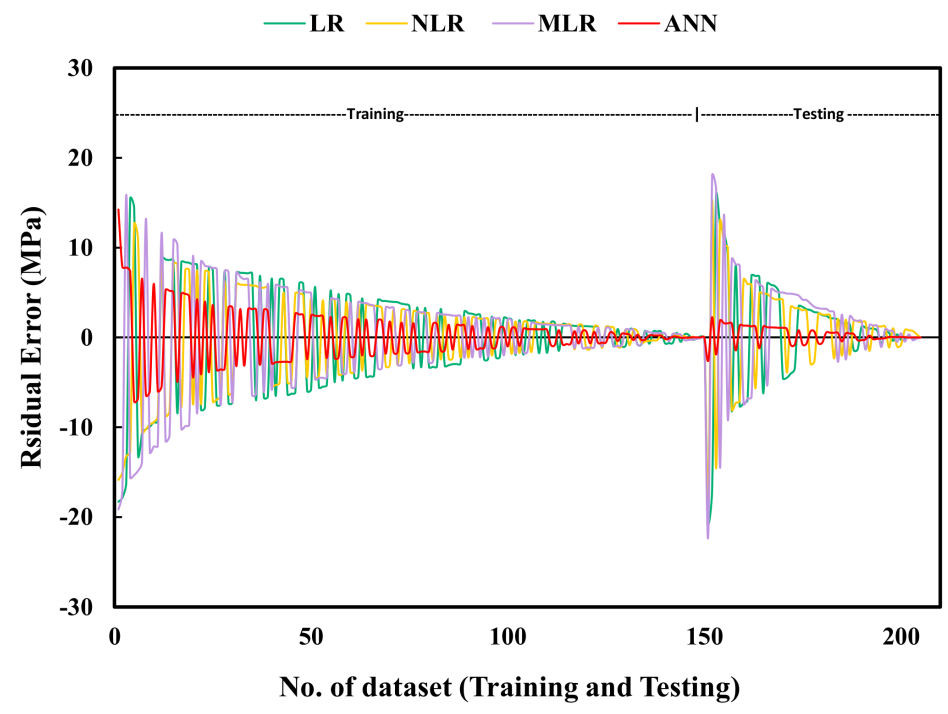

Figure 15. Residual error comparison of the models predicted the compressive strength of cement paste with nanosilica (NS) and microsilica (MS).

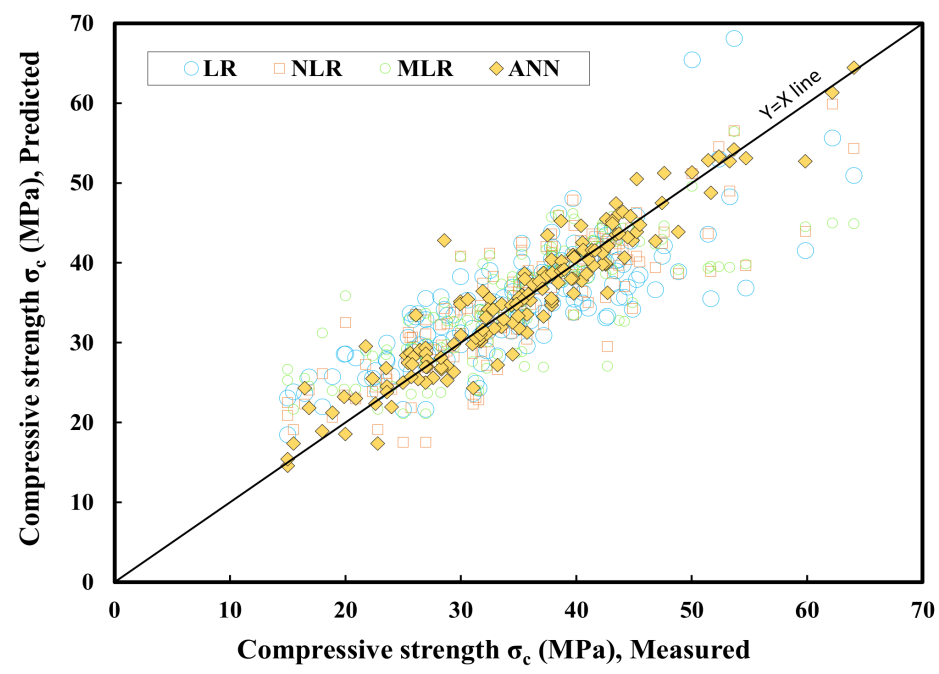

Figure 16. Superposition of measured and predicted value comparison between predicted models.

\subsubsection{Sensitivity of Parameters}

A sensitivity comparison for the models was conducted to find and evaluate the most impacting component affecting the compressive strength of paste mixtures adjusted with NS and MS [48]. By looking at the other equations, we could see that NS parameters were more significant than the MS additive, which shows NS's, effect to have been greater than MS. However, the most efficient model, ANN, was chosen for the sensitivity analysis. During the investigation, all the training datasets were used for each time, and a single input variable was extracted at a time for each set. For each attempt separately, the evaluation parameters such as R2, RMSE, and MAE were determined. Figure 10 summarizes the findings of the sensitivity analysis. The findings indicated that the curing time was the most critical and influential variable in predicting the compressive strength of paste mixes treated with NS and MS. This study also derived that the NS was more sensitive than the MS additive to the compressive strength of the cement-based paste. According to the obtained R2 value from that analysis, the NS sensitivity was $6.3 \%$ more than the MS additive.

It is worth mentioning that the further use of machine learning techniques in various application domains, e.g., foundation and pavements, can be of significant importance [50,51]. In this regard, using deep learning [52] could bring further novelty and complement our 
research. However, one of the study's limitations was the life cycle assessment, reclaimed materials, and life cycle cost analysis for design innovation [52-55]. As mentioned, case studies on the specific application domains would be essential for the validation of the real-life performance as earlier investigated in the case of pavements [56-60]. Nevertheless, using novel machine learning methods such as hybrids and ensembles would be essential for future research for improving the model performance [61,62]. Training the machine learning methods with powerful evolutionary optimization techniques would be another approach to improving the models' quality [63-67].

\section{Conclusions}

Accurate and valid models for compressive strength prediction may result in substantial cost and time savings. According to the results achieved from this study, nanosilica highly affected the compressive strength of cement paste compared to microsilica. The curing time was the most significant parameter that caused an improvement in the compressive strength of the cement paste. The following findings could be drawn from the study and modeling of data from prior research used to predict the compressive strength of cement paste mixes modified with NS and MS in various combined proportions. Firstly, the relationship between the effective parameters on the compressive strength of cement paste mixtures was investigated with four different LR, NLR, MLR, and ANN models. Secondly, the ANN model worked better than other models with a greater $\mathrm{R}^{2}$ value, lower RMSE, lower OBJ, and lower MAE values, and an excellent performance value of SI for training and testing datasets based upon the various evaluation parameters. In addition, the LR, NLR, MLR, and ANN models were the models built in this research to forecast the compressive strength of the cement paste. Based on the various evaluation parameters such as $\mathrm{R}^{2}$, RMSE, MAE, SI, and OBJ, results indicated that the sequence of models was LR, NLR, MLR, and ANN, which meant that the ANN model was the best model proposed in this study based on data collected from literature, giving higher $\mathrm{R}^{2}$ and lower RMSE and MAE values. SI values ranged from 0.03 to 0.2 , suggesting good model results for all models and phases (training and testing). In addition, the ANN model had an SI value lower by $43.7 \%$ and $35.7 \%$ in the training process than the LR model and the NLR model. The OBJ value of the model for ANN was $46.5 \%$ lower than that of the NLR. This also shows that the ANN model was more effective for estimating the NS and MS compressive strength in paste mixtures. A sensitivity study showed that nanosilica was $6.3 \%$ more sensitive than MS as the most significant additive component for predicting paste mixtures' compression strength adjusted with nano or microsilica. In the future, research could be presented on the evaluation of the efficiency of different systematic models to predict the effect of the micro and nano size of $\mathrm{SiO}_{2}$ on the porosity of cement mortar and paste as an essential factor on the compressive strength and durability of cementitious materials.

Author Contributions: Conceptualization, C.Y.R. and A.S.; methodology, C.Y.R. and A.S.; software, C.Y.R. and A.S.; validation, C.Y.R. and A.S.; formal analysis, C.Y.R. and A.S.; investigation, C.Y.R. and A.S.; resources, C.Y.R.; data curation, C.Y.R.; writing original draft preparation, C.Y.R.; writing review and editing, A.S. and A.A.B.; visualization, A.S.; supervision, A.S. and A.A.B.; project administration, A.S. and A.A.B. All authors have read and agreed to the published version of the manuscript.

Funding: This research received no external funding.

Institutional Review Board Statement: Not applicable for studies not involving humans or animals.

Informed Consent Statement: Informed consent was obtained from all subjects involved in the study.

Conflicts of Interest: The authors declare no conflict of interest. 


\section{References}

1. Seifan, M.; Mendoza, S.; Berenjian, A. Mechanical properties and durability performance of fly ash based mortar containing nano-and micro-silica additives. Constr. Build. Mater. 2020, 252, 119121. [CrossRef]

2. Senff, L.; Hotza, D.; Labrincha, J. Effect of diatomite addition on fresh and hardened properties of mortars investigated through mixture experiments. Adv. Appl. Ceram. 2011, 110, 142-150. [CrossRef]

3. Ahmed, H.U.; Mohammed, A.A.; Rafiq, S.; Mohammed, A.S.; Mosavi, A.; Sor, N.H.; Qaidi, S. Compressive Strength of Sustainable Geopolymer Concrete Composites: A State-of-the-Art Review. Sustainability 2021, 13, 13502. [CrossRef]

4. Ghosh, A.; Ghosh, A.; Neogi, S. Reuse of fly ash and bottom ash in mortars with improved thermal conductivity performance for buildings. Heliyon 2018, 4, e00934. [CrossRef] [PubMed]

5. Darban, S.; Tehrani, H.G.; Karballaeezadeh, N.; Mosavi, A. Application of analytical hierarchy process for Structural Health Monitoring and Prioritizing of Concrete Bridges in Iran. Appl. Sci. 2021, 11, 8086. [CrossRef]

6. Shaikh, F.; Supit, S.; Sarker, P. A study on the effect of nano silica on compressive strength of high volume fly ash mortars and concretes. Mater. Des. 2014, 60, 433-442. [CrossRef]

7. Kumar, R.; Mohd Yaseen, A.Y.B.; Shafiq, N.; Jalal, A. Influence of metakaolin, fly ash and nano silica on mechanical and durability properties of concrete. Key Eng. Mater. 2021, 11, 8-14. [CrossRef]

8. Mohsen, M.O.; Al Ansari, M.S.; Taha, R.; Al Nuaimi, N.; Taqa, A.A. Carbon nanotube effect on the ductility, flexural strength, and permeability of concrete. J. Nanomater. 2019, 2019, 1452. [CrossRef]

9. Morsy, M.; Al-Salloum, Y.; Almusallam, T.; Abbas, H. Effect of nano-metakaolin addition on the hydration characteristics of fly ash blended cement mortar. J. Therm. Anal. Calorim. 2014, 116, 845-852. [CrossRef]

10. Ali Khan, M.; Zafar, A.; Akbar, A.; Javed, M.F.; Mosavi, A. Application of Gene Expression Programming (GEP) for the prediction of compressive strength of geopolymer concrete. Materials 2021, 14, 1106. [CrossRef]

11. Kumar, R.; Shafiq, N.; Kumar, A.; Jhatial, A.A. Investigating embodied carbon, mechanical properties, and durability of highperformance concrete using ternary and quaternary blends of metakaolin, nano-silica, and fly ash. Environ. Sci. Pollut. Res. 2021, 28, 49074-49088. [CrossRef] [PubMed]

12. Shahbazpanahi, S.; Tajara, M.K.; Faraj, R.H.; Mosavi, A. Studying the C-H Crystals and Mechanical Properties of Sustainable Concrete Containing Recycled Coarse Aggregate with Used Nano-Silica. Crystals 2021, 11, 122. [CrossRef]

13. Karunarathne, V.K.; Paul, S.C.; Šavija, B. Development of nano-SiO 2 and bentonite-based mortars for corrosion protection of reinforcing steel. Materials 2019, 12, 2622. [CrossRef] [PubMed]

14. Pourjavadi, A.; Fakoorpoor, S.M.; Khaloo, A.; Hosseini, P. Improving the performance of cement-based composites containing superabsorbent polymers by utilization of nano-SiO 2 particles. Mater. Des. 2012, 42, 94-101. [CrossRef]

15. Kim, K.-M.; Heo, Y.-S.; Kang, S.-P.; Lee, J. Effect of sodium silicate-and ethyl silicate-based nano-silica on pore structure of cement composites. Cem. Concr. Compos. 2014, 49, 84-91. [CrossRef]

16. Abbasi, S.; Jannaty, M.H.; Faraj, R.H.; Shahbazpanahi, S.; Mosavi, A. The effect of incorporating silica stone waste on the mechanical properties of sustainable concretes. Materials 2020, 13, 3832. [CrossRef] [PubMed]

17. Vickers, N.J. Animal communication: When i'm calling you, will you answer too? Curr. Biol. 2017, 27, R713-R715. [CrossRef] [PubMed]

18. Shah, M.; Amin, M.; Khan, K.; Niazi, M.; Aslam, F.; Alyousef, R.; Javed, M.; Mosavi, A. Performance Evaluation of Soft Computing for Modeling the Strength Properties of Waste Substitute Green Concrete. Sustainability 2021, 13, 2867. [CrossRef]

19. Maravelaki-Kalaitzaki, P.; Agioutantis, Z.; Lionakis, E.; Stavroulaki, M.; Perdikatsis, V. Physico-chemical and mechanical characterization of hydraulic mortars containing nano-titania for restoration applications. Cem. Concr. Compos. 2013, $36,33-41$. [CrossRef]

20. Mohseni, E.; Miyandehi, B.M.; Yang, J.; Yazdi, M.A. Single and combined effects of nano- $\mathrm{SiO}_{2}$, nano- $\mathrm{Al}_{2} \mathrm{O}_{3}$ and nano-TiO ${ }_{2}$ on the mechanical, rheological and durability properties of self-compacting mortar containing fly ash. Constr. Build. Mater. 2015, 84, 331-340. [CrossRef]

21. Ahmad, J.; Tufail, R.F.; Aslam, F.; Mosavi, A.; Alyousef, R.; Faisal Javed, M.; Zaid, O.; Khan Niazi, M.S. A step towards sustainable self-compacting concrete by using partial substitution of wheat straw ash and bentonite clay instead of cement. Sustainability 2021, 13, 824. [CrossRef]

22. Madandoust, R.; Mohseni, E.; Mousavi, S.Y.; Namnevis, M. An experimental investigation on the durability of self-compacting mortar containing nano- $\mathrm{SiO}_{2}$, nano- $\mathrm{Fe}_{2} \mathrm{O}_{3}$ and nano-CuO. Constr. Build. Mater. 2015, 86, 44-50. [CrossRef]

23. Horszczaruk, E.; Aleksandrzak, M.; Cendrowski, K.; Jędrzejewski, R.; Baranowska, J.; Mijowska, E. Mechanical properties cement based composites modified with nano- $\mathrm{Fe}_{3} \mathrm{O}_{4} / \mathrm{SiO}_{2}$. Constr. Build. Mater. 2020, 251, 118945. [CrossRef]

24. Qing, Y.; Zenan, Z.; Deyu, K.; Rongshen, C. Influence of nano-SiO 2 addition on properties of hardened cement paste as compared with silica fume. Constr. Build. Mater. 2007, 21, 539-545. [CrossRef]

25. Wang, L.; Zheng, D.; Zhang, S.; Cui, H.; Li, D. Effect of nano-SiO 2 on the hydration and microstructure of Portland cement. Nanomaterials 2016, 6, 241. [CrossRef]

26. Li, L.; Huang, Z.; Zhu, J.; Kwan, A.; Chen, H. Synergistic effects of micro-silica and nano-silica on strength and microstructure of mortar. Constr. Build. Mater. 2017, 140, 229-238. [CrossRef]

27. Sajedi, F.; Razak, H.A. Comparison of different methods for activation of ordinary Portland cement-slag mortars. Constr. Build. Mater. 2011, 25, 30-38. [CrossRef] 
28. Mala, A.A.; Sherwani, A.F.H.; Younis, K.H.; Faraj, R.H.; Mosavi, A. Mechanical and fracture parameters of ultra-high performance fiber reinforcement concrete cured via steam and water: Optimization of binder content. Materials 2021, 14, 2016. [CrossRef]

29. Piro, N.S.; Salih, A.; Hamad, S.M.; Kurda, R. Comprehensive multiscale techniques to estimate the compressive strength of concrete incorporated with carbon nanotubes at various curing times and mix proportions. J. Mater. Res. Technol. 2021, 15, 6506-6527. [CrossRef]

30. Ashrafian, A.; Taheri Amiri, M.J.; Masoumi, P.; Asadi-shiadeh, M.; Yaghoubi-chenari, M.; Mosavi, A.; Nabipour, N. Classificationbased regression models for prediction of the mechanical properties of roller-compacted concrete pavement. Appl. Sci. 2020, 10, 3707. [CrossRef]

31. Ghafor, K.; Qadir, S.; Mahmood, W.; Mohammed, A. Statistical variations and new correlation models to predict the mechanical behaviour of the cement mortar modified with silica fume. Geomech. Geoengin. 2020, 14, 1-13. [CrossRef]

32. Navabi, D.; Javidruzi, M.; Hafezi, M.R.; Mosavi, A. The high-performance light transmitting concrete and experimental analysis of using polymethylmethacrylate optical fibers in it. J. Build. Eng. 2021, 38, 102076. [CrossRef]

33. Kooshkaki, A.; Eskandari-Naddaf, H. Effect of porosity on predicting compressive and flexural strength of cement mortar containing micro and nano-silica by multi-objective ANN modeling. Constr. Build. Mater. 2019, 212, 176-191. [CrossRef]

34. Setiati, N.R. Effects of additional nanosilica of compressive strength on mortar. Mater. Sci. Eng. 2021, 11, 012065.

35. Bekem Kara, İ.; Durmuş, Ö.F. Effect of nano silica on cement mortars containing micro silica. Chall. J. Concr. Res. Lett. 2019, 10, 42-49. [CrossRef]

36. Habeeb, G.M.; Ghali, Z.A.S. Effect of Accelerated Curing on Compressive Strength of High Strength Concrete with Nano-Silica. Available online: https://www.researchgate.net/profile/Ghalib-Habeeb/publication/309734552_EFFECT_OF_ACCELERATED_ CURING_ON_COMPRESSIVE_STRENGTH_OF_HIGH_STRENGTH_CONCRETE_WITH_NANO-_SILICA/links/5820a4 7808ae12715afbc867/EFFECT-OF-ACCELERATED-CURING-ON-COMPRESSIVE-STRENGTH-OF-HIGH-STRENGTHCONCRETE-WITH-NANO-SILICA.pdf (accessed on 30 September 2021).

37. Garg, R.; Garg, R.; Bansal, M.; Aggarwal, Y. Experimental study on strength and microstructure of mortar in presence of micro and nano-silica. Mater. Today Proc. 2021, 43, 769-777. [CrossRef]

38. Golafshani, E.M.; Behnood, A.; Arashpour, M. Predicting the compressive strength of normal and High-Performance Concretes using ANN and ANFIS hybridized with Grey Wolf Optimizer. Constr. Build. Mater. 2020, 232, 117266. [CrossRef]

39. FM Zain, M.; Abd, S. Multiple regression model for compressive strength prediction of high performance concrete. J. Appl. Sci. 2009, 9, 155-160. [CrossRef]

40. Mohammed, A.; Mahmood, W.; Ghafor, K. TGA, rheological properties with maximum shear stress and compressive strength of cement-based grout modified with polycarboxylate polymers. Constr. Build. Mater. 2020, 235, 117534. [CrossRef]

41. Sarwar, W.; Ghafor, K.; Mohammed, A. Modeling the rheological properties with shear stress limit and compressive strength of ordinary Portland cement modified with polymers. J. Build. Pathol. Rehabil. 2019, 4, 25. [CrossRef]

42. Vipulanandan, C.; Mohammed, A.; Ganpatye, A. Smart cement performance enhancement with $\mathrm{NanoAl}_{2} \mathrm{O}_{3}$ for real time monitoring applications using Vipulanandan models. Offshore Technol. 2021, 12, 123.

43. Li, M.-F.; Tang, X.-P.; Wu, W.; Liu, H.-B. General models for estimating daily global solar radiation for different solar radiation zones in mainland China. Energy Convers. Manag. 2013, 70, 139-148. [CrossRef]

44. Mohammed, A.; Rafiq, S.; Mahmood, W.; Noaman, R.; Ghafor, K.; Qadir, W.; Kadhum, Q. Characterization and modeling the flow behavior and compression strength of the cement paste modified with silica nano-size at different temperature conditions. Constr. Build. Mater. 2020, 257, 119590. [CrossRef]

45. Burhan, L.; Ghafor, K.; Mohammed, A. Enhancing the fresh and hardened properties of the early age concrete modified with powder polymers and characterized using different models. Adv. Civ. Eng. Mater. 2020, 9, 227-249. [CrossRef]

46. Almohammad-albakkar, M.; Behfarnia, K. Effects of the combined usage of micro and nano-silica on the drying shrinkage and compressive strength of the self-compacting concrete. J. Sustain. Cem.-Based Mater. 2020, 41, 1-19. [CrossRef]

47. Afzali-Naniz, O.; Mazloom, M. Fracture behavior of self-compacting semi-lightweight concrete containing nano-silica. Adv. Struct. Eng. 2019, 22, 2264-2277. [CrossRef]

48. Mohammed, A.; Rafiq, S.; Sihag, P.; Kurda, R.; Mahmood, W. Soft computing techniques: Systematic multiscale models to predict the compressive strength of HVFA concrete based on mix proportions and curing times. J. Build. Eng. 2020, $2020,101851$. [CrossRef]

49. Thomas, M. Supplementary Cementing Materials in Concrete; CRC Press: Boca Raton, FL, USA, 2013.

50. Moayedi, H.; Mosavi, A. A water cycle-based error minimization technique in predicting the bearing capacity of shallow foundation. Eng. Comput. 2021, 14, 1-14. [CrossRef]

51. Perez, H.; Tah, J.H.; Mosavi, A. Deep learning for detecting building defects using convolutional neural networks. Sensors 2019, 19, 3556. [CrossRef] [PubMed]

52. Alaloul, W.S.; Altaf, M.; Musarat, M.A.; Faisal Javed, M.; Mosavi, A. Systematic Review of Life Cycle Assessment and Life Cycle Cost Analysis for Pavement and a Case Study. Sustainability 2021, 13, 4377. [CrossRef]

53. Mosavi, A.; Rabczuk, T. Learning and intelligent optimization for material design innovation. Learn. Intell. Optim. 2017, 14, 358-363.

54. Gomez, C.; Oller, J.; Paradells, J. Sensors-12-11734-Naam van de docent. Sensors 2012, 12, 11734-11753. [CrossRef] 
55. Awan, H.H.; Javed, M.F.; Yousaf, A.; Aslam, F.; Alabduljabbar, H.; Mosavi, A. Experimental Evaluation of Untreated and Pretreated Crumb Rubber Used in Concrete. Crystals 2021, 11, 558. [CrossRef]

56. Band, S.S.; Mosavi, A.; Reuter, U. Smart Structural Health Monitoring of Flexible Pavements Using Machine Learning Methods. Coatings 2020, 10, 1100.

57. Mohammadzadeh, S.D.; Kazemi, S.-F.; Mosavi, A.; Nasseralshariati, E.; Tah, J.H. Prediction of compression index of fine-grained soils using a gene expression programming model. Infrastructures 2019, 4, 26. [CrossRef]

58. Haji-Savameri, M.; Norouzi-Apourvari, S.; Irannejad, A.; Hemmati-Sarapardeh, A.; Schaffie, M.; Mosavi, A. Experimental study and modelling of asphaltene deposition on metal surfaces with superhydrophobic and low sliding angle inner coatings. Sci. Rep. 2021, 11, 16812. [CrossRef]

59. Shojaei, S.; Shojaei, S.; Band, S.S.; Farizhandi, A.A.K.; Ghoroqi, M.; Mosavi, A. Application of Taguchi method and response surface methodology into the removal of malachite green and auramine-O by NaX nanozeolites. Sci. Rep. 2021, 11, 16054. [CrossRef]

60. Riahi-Madvar, H.; Dehghani, M.; Seifi, A.; Salwana, E.; Shamshirband, S.; Mosavi, A.; Chau, K.-w. Comparative analysis of soft computing techniques RBF, MLP, and ANFIS with MLR and MNLR for predicting grade-control scour hole geometry. Eng. Appl. Comput. Fluid Mech. 2019, 13, 529-550. [CrossRef]

61. Mahmoudi, M.R.; Baleanu, D.; Qasem, S.N.; Mosavi, A.; Band, S.S. Testing the equality of several independent stationary and non-stationary time series models with fractional Brownian motion errors. Alex. Eng. J. 2021, 60, 1767-1775. [CrossRef]

62. Chen, H.; Heidari, A.A.; Chen, H.; Wang, M.; Pan, Z.; Gandomi, A.H. Multi-population differential evolution-assisted Harris hawks optimization: Framework and case studies. Future Gener. Comput. Syst. 2020, 111, 175-198. [CrossRef]

63. Hu, J.; Chen, H.; Heidari, A.A.; Wang, M.; Zhang, X.; Chen, Y.; Pan, Z. Orthogonal learning covariance matrix for defects of grey wolf optimizer: Insights, balance, diversity, and feature selection. Knowl.-Based Syst. 2021, 213, 106684. [CrossRef]

64. Zhang, Y.; Liu, R.; Heidari, A.A.; Wang, X.; Chen, Y.; Wang, M.; Chen, H. Towards augmented kernel extreme learning models for bankruptcy prediction: Algorithmic behavior and comprehensive analysis. Neurocomputing 2021, 430, 185-212. [CrossRef]

65. Zhao, D.; Liu, L.; Yu, F.; Heidari, A.A.; Wang, M.; Liang, G.; Muhammad, K.; Chen, H. Chaotic random spare ant colony optimization for multi-threshold image segmentation of 2D Kapur entropy. Knowl.-Based Syst. 2021, 216, 106510. [CrossRef]

66. Shan, W.; Qiao, Z.; Heidari, A.A.; Chen, H.; Turabieh, H.; Teng, Y. Double adaptive weights for stabilization of moth flame optimizer: Balance analysis, engineering cases, and medical diagnosis. Knowl.-Based Syst. 2021, 214, 106728. [CrossRef]

67. Tu, J.; Chen, H.; Liu, J.; Heidari, A.A.; Zhang, X.; Wang, M.; Ruby, R.; Pham, Q.-V. Evolutionary biogeography-based whale optimization methods with communication structure: Towards measuring the balance. Knowl.-Based Syst. 2021, $212,106642$. [CrossRef] 